\title{
Role of Antecedent Land Surface Conditions on North American Monsoon Rainfall Variability*
}

\author{
Chunmei Zhu and Dennis P. Lettenmaier \\ Department of Civil and Environmental Engineering, University of Washington, Seattle, Washington \\ Tereza Cavazos \\ Department of Physical Oceanography, CICESE, Ensenada, Mexico
}

(Manuscript received 31 March 2004, in final form 1 November 2004)

\begin{abstract}
Possible links between North American Monsoon System (NAMS) seasonal [June-July-AugustSeptember (JJAS)] precipitation and premonsoon seasonal land surface conditions including precipitation $(\mathrm{P})$, surface air temperature (Ts), soil moisture $(\mathrm{Sm})$, and snow water equivalent (SWE) anomalies are explored during the 1950-2000 period. A statistically significant inverse relationship is found between monsoon precipitation in an area defined as the Monsoon West (Arizona and western New Mexico) and antecedent winter precipitation in the southwestern (SW) United States and the mountainous region in Utah and Colorado (the predictor area). This linkage is strong during 1965-90 and weak otherwise, as has been suggested by previous studies. A land surface feedback hypothesis is proposed to explain this relationship: more winter P leads to more winter and early spring SWE in the predictor area, hence more spring and early summer Sm, and lower spring and early summer Ts, which induces a weaker onset (and less precipitation) of the NAMS and vice versa. All three links in this hypothesis were tested and the existence of a land memory associated with winter precipitation and snow, which can persist until June, was confirmed. However, the results show that this land memory contributes little to the magnitude of NAM precipitation. Winter snow is negatively correlated to late spring Ts in the SW mountainous region, but not in extreme years. In fact, the premonsoon (June) Ts over the U.S. southwest is inversely related to monsoon precipitation, which is the reverse of what is expected based on the hypothesis. The lack of a significant Sm-Ts-P relationship in most of the SW suggests, based on the constructed Sm dataset, that local premonsoon soil wetness conditions play a minor role in the strength of the monsoon. A strong positive relationship between June Ts anomalies and the large-scale midtropospheric circulation before the onset of the monsoon was found, suggesting that the controlling factor for the premonsoon Ts anomalies may not be local (i.e., not from the land surface). The results suggest that further research is needed to elucidate the nature of land-sea-atmosphere interactions as related to the onset of the monsoon.
\end{abstract}

\section{Introduction}

The North American Monsoon System (NAMS) has a great socioeconomic impact on the semiarid regions of the southwestern (SW) United States and northwestern Mexico. Between $40 \%$ and $80 \%$ of the annual pre-

\footnotetext{
* Joint Institute for the Study of the Atmosphere and Ocean Contribution Number 1063.
}

Corresponding author address: Dr. Dennis P. Lettermaier, Department of Civil and Environmental Engineering, University of Washington, Box 352700, Seattle, WA 98195.

E-mail: dennisl@u.washington.edu cipitation in this region falls during the [June-JulyAugust-September (JJAS)] monsoon season (Stensrud et al. 1997) and exhibits large year-to-year variability. In the most arid regions of the SW such as Arizona and New Mexico, this interannual variability tends to be larger than the mean seasonal rainfall itself (Higgins et al. 1998). The SW is particularly sensitive to summer climate and weather extremes, which produce hazards such as flash flooding and drought because of the region's steep terrain and poor soil moisture-holding capacity. These conditions in turn adversely affect infrastructure, agricultural production, water supply, and hydroelectric power generation (Castro et al. 2001). This sensitivity to extreme conditions is likely to in- 
crease with continued population growth and urbanization pressures on this region. Therefore, there is a critical need to improve the seasonal predictability of the NAM precipitation: a better prediction could help mitigate the region's susceptibility to natural hazards.

Seasonal changes in the thermal contrast between land and adjacent oceanic regions are a cornerstone of the conceptual basis for understanding NAMS (Adams and Comrie 1997; Higgins et al. 1998; Gutzler 2000). The combination of seasonally warm land surfaces in lowlands and elevated areas together with atmospheric moisture supplied by nearby maritime sources is conductive to the formation of a monsoonlike system (Adams and Comrie 1997). Given this apparent dependence on (land and ocean) surface conditions, a promising method for predicting NAM precipitation is to use information of premonsoon land surface and oceanic conditions (e.g., precipitation, surface air temperature, soil moisture, snow cover, sea surface temperature, etc.) and relate them to monsoon precipitation. Thus, to develop useful seasonal monsoon climate prediction capabilities, the first step is to explore and find the possible significant links between the NAMS and the above-mentioned antecedent conditions.

Even though the picture is far from complete, understanding the role of ocean conditions on the NAMS has been the building block on which progress in monsoon climate forecasting is based. Some studies suggest that both equatorial Pacific and North Pacific oceanic anomalies partially modulate North American monsoon circulation (Mo and Paegle 2000; Castro et al. 2001). Other studies also document that sea surface temperatures (SSTs) in the tropical Pacific alone cannot explain the rainfall variability in the SW (Carleton et al. 1990; Harrington et al. 1992; Higgins et al. 2000). Nonetheless, the role of land surface feedbacks in modulating warm season NAM precipitation is still uncertain (e.g., Gutzler and Preston 1997; Higgins et al. 1998; Gutzler 2000; Small 2001; Hu and Feng 2002; Lo and Clark 2002; Matsui et al. 2003).

Higgins et al. (1998, 2000) document the connection between antecedent wintertime precipitation along the west coast of the United States and monsoon precipitation in the SW. Wet (dry) southwest monsoons are preceded by winters characterized by dry (wet) conditions in the SW and wet (dry) conditions in the Pacific Northwest. Therefore, SW winter precipitation could be a potential predictor for summer monsoon precipitation. This relationship has been attributed by various authors to the ocean memory that the Pacific SST anomalies impart to the atmosphere without examining the role of the land surface. Hu and Feng (2002) tested the robustness of the inverse relationship of SW win- ter-summer precipitation documented by Higgins et al. $(1998,2000)$ and found that such relationship was not robust during the entire twentieth century. The correlation was statistically significant only during the periods 1920-30 and 1960-90. This fluctuation was identified as a multidecadal variation of the atmospheric circulation in the Pacific-North American (PNA) sector. Although $\mathrm{Hu}$ and Feng (2002) argue that land memory contributes to this variation, no direct evidence from land surface conditions was presented.

Almost a century ago, Walker (1910) found an inverse relationship between the end of May Himalayan snow depth and summer monsoon precipitation in India, and Himalayan snow conditions have ever since been used as one predictor in applied forecasting of the Indian monsoon (Bamzai and Shukla 1999). Later, a considerable body of observational and modeling evidence was developed that supported the role of spring snow cover across Eurasia in modulating the amplitude of the following summer's monsoon rainfall across Southeast Asia (e.g., Barnett et al. 1989; Bamzai and Shukla 1999). The physical basis for the Eurasian snow cover-monsoon relationship is derived from a land memory effect (Shukla and Mooley 1987). Strong winter and early spring snowpack act as an energy sink that inhibits snow melting and evaporation of soil moisture in spring and early summer. High albedo due to strong winter snowpack plays a reinforcing role for this energy sink. All these factors reduce the summertime land surface heating that drives the monsoon circulation. Based on these studies, Gutzler and Preston (1997) first hypothesized an analogous spring snowpack-summer monsoon relationship in North America. Their study showed that there is a weak negative correlation between spring snow extent across the western and central United States and the subsequent summer's rainfall averaged over the state of New Mexico. In a more recent work, Gutzler (2000) identified three distinct snow-rainfall subregions, but only one subregion in New Mexico was characterized by an inverse relationship between snowpack and monsoon rainfall, suggesting that the main physical mechanisms that modulate monsoon rainfall vary across the NAM region. Moreover, Gutzler (2000) also found that a strong spring snow-monsoon precipitation correlation only existed during 1960-90, and broke down before and after this period, consistent with $\mathrm{Hu}$ and Feng's (2002) results based on winter-summer precipitation. Lo and Clark (2002) performed a detailed analysis of the relationship between snowpack in the mountain areas of the western United States and monsoon precipitation in the SW. Their results also confirmed the existence of an inverse relationship between winter snow and monsoon 


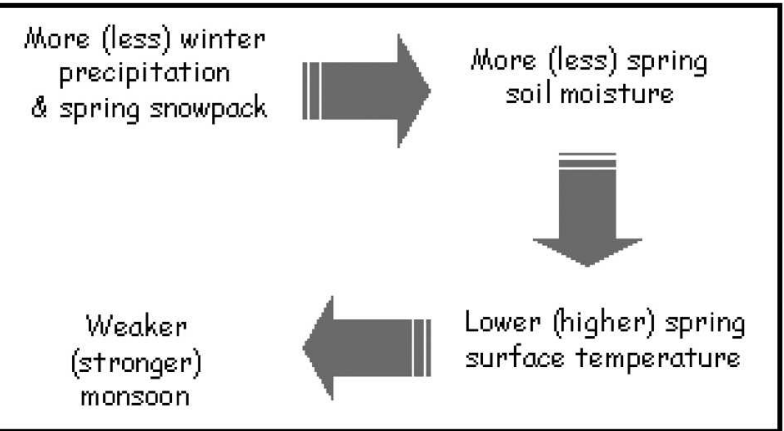

FIG. 1. Proposed winter-summer land surface-atmosphere feedback hypothesis for NAM.

precipitation in the SW, but this relationship was not stable from 1947 to 1997.

Although the works cited above confirm an inverse relationship between winter precipitation and spring snowpack with summer precipitation, little is known about the physical mechanisms for such a connection in the NAM region. All these studies suggest a possible land memory effect, but there is no further evidence for this hypothesis, partly because of the lack of observed soil moisture data. As a surrogate, Small (2001) examined the influence of soil moisture anomalies on the variability of the NAM using the fifth-generation Pennsylvania State University-National Center for Atmospheric Research (PSU-NCAR) Mesoscale Model (MM5) linked to the Oregon State University (OSU) land surface scheme. His modeling results are consistent with the observed inverse relationship between southern Rocky Mountains snowpack and monsoon rainfall documented by Gutzler and Preston (1997) and Gutzler (2000), and thus support the snow-soil moisture-monsoon rainfall hypothesis. However, the soil moisture prescribed in Small's simulations seems excessive (exceeds field capacity) and this anomalously high soil moisture persists throughout the summer season, which calls into question the realism of the modeling results. On the other hand, Matsui et al. (2003) also showed that there is an inverse relationship between April SWE in the Southern Rocky Mountain region and subsequent spring temperatures that persist into June. However, they concluded that this inverse relationship could not directly influence monsoon rainfall in July and August because it disappears during the monsoon season.

To date, the role of the land surface in NAMS is still a puzzle. The important scientific question, to what extent the land surface affects atmosphere, has not been addressed in detail because of the lack of long-term soil moisture data. Soil moisture plays an important role in land surface-atmosphere interactions by controlling the magnitude of the surface-atmosphere water and energy fluxes (Yeh et al. 1984; Entekhabi et al. 1992). To examine the land surface feedback mechanism, it is necessary to represent soil moisture as a link between precipitation and surface temperature. The retrospective Land Data Assimilation System (LDAS) dataset of Maurer et al. (2002), which was derived through the application of a macroscale land surface model known as Variable Infiltration Capacity (VIC) and run offline

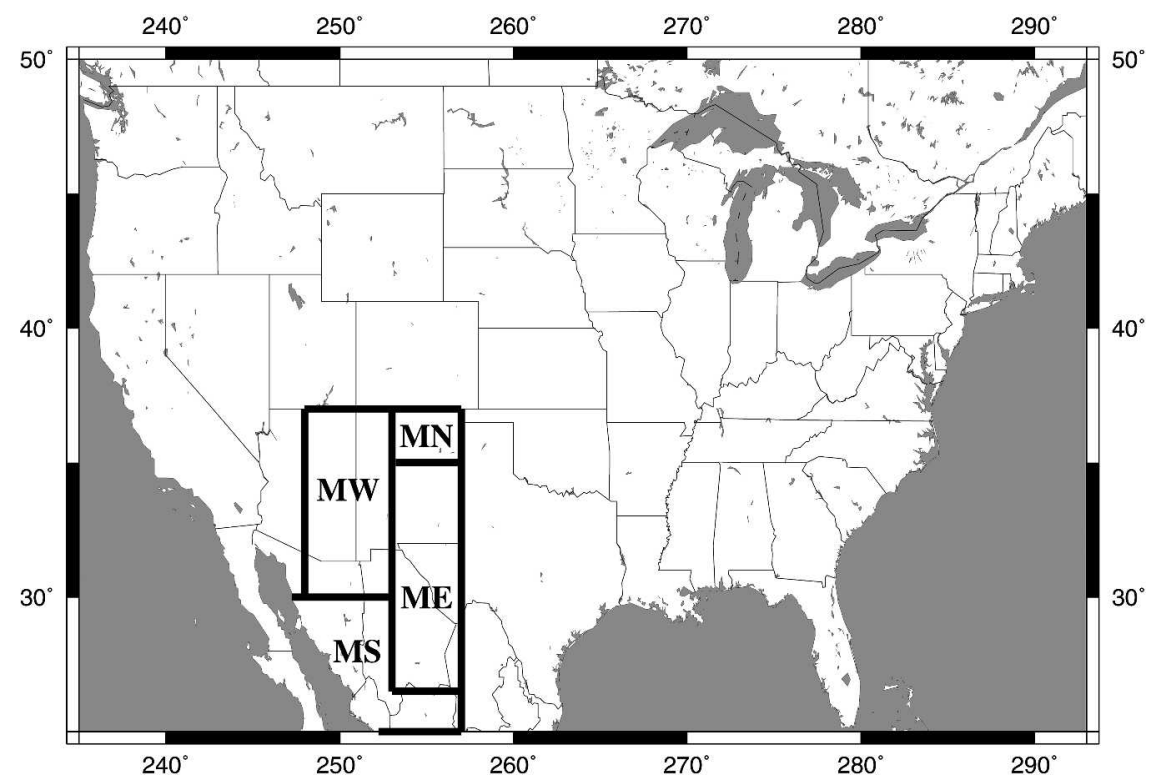

FIG. 2. Study land domain $\left(25^{\circ}-50^{\circ} \mathrm{N}, 235^{\circ}-293^{\circ} \mathrm{E}\right)$ and monsoon regions. 

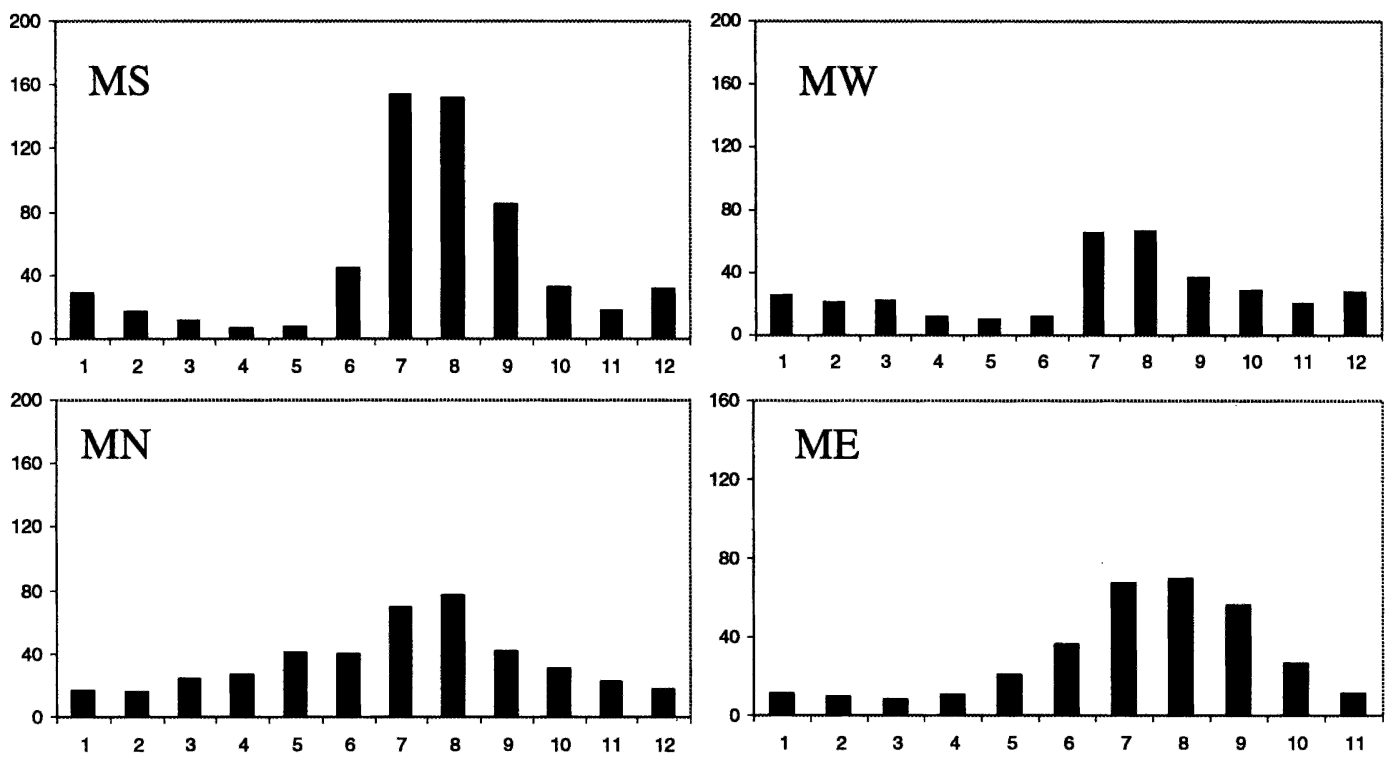

FIG. 3. Monsoon regions long-term monthly area mean precipitation (mm) during 1950-99.

with observed surface forcings (described in detail in the next section), provides a means to explore such links because it covers a lengthy period of record (1950-99) and the entire continental United States and northern Mexico (above latitude $25^{\circ} \mathrm{N}$ ). In one case where long records of observed soil moisture were available (over Illinois), Maurer et al. (2002) showed that the variability of LDAS soil moisture matches that of observations quite well. Pan et al. (2003) compared snow water equivalent (SWE) predictions from four land surface models including VIC with observations in the western United States, and found that VIC had the smallest bias among the four models considered. Maurer et al. (2002) showed a slight overestimation of late-

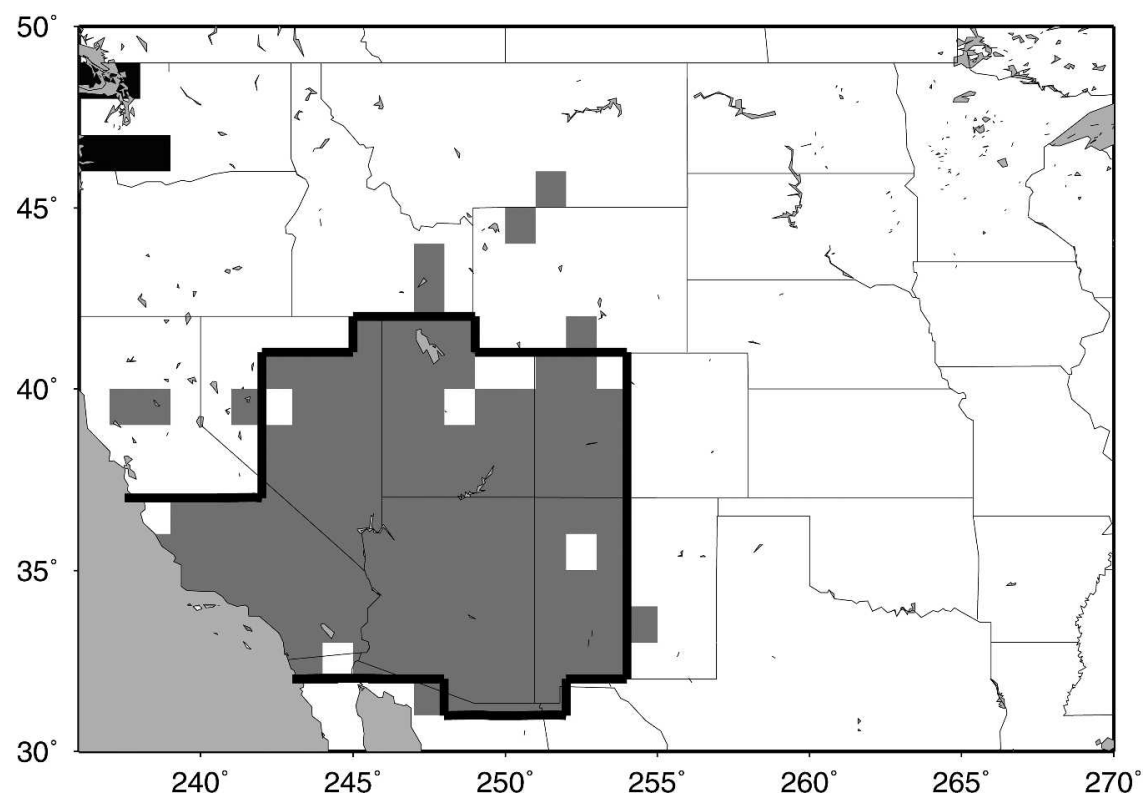

FIG. 4. Correlation between MW JJAS monsoon precipitation and antecedent JFM precipitation in the entire domain during 1965-99. Significant correlations at the 5\% level or greater are shaded (gray, $<-0.33$ or dark, $>0.33$ ). The region in the box is defined as the MW winter precipitation-related region. 


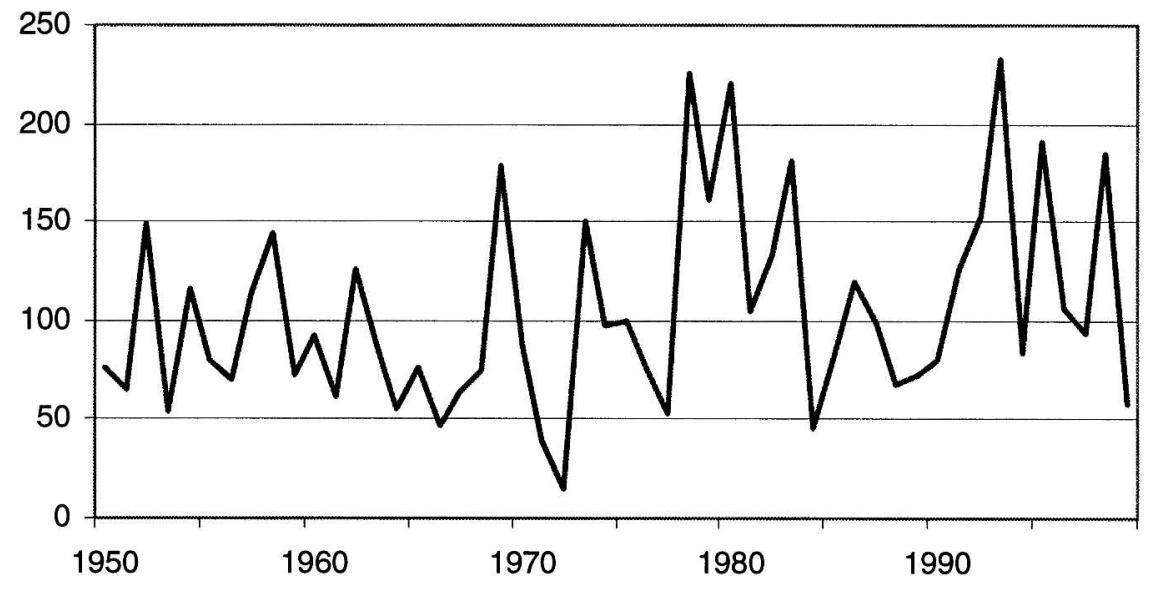

FIG. 5. Winter (JFM) precipitation index for MW.

season snow in the VIC simulations relative to observations in the western United States. Other papers (e.g., Abdulla et al. 1996; Nijssen et al. 2001) have demonstrated the ability of the model to reproduce land surface hydrologic state variables (soil moisture, SWE) over large areas of the continental United States. The reproducibility of the LDAS land surface dataset to some extent ensures the reliability of the analyses on the land surface feedback mechanism.

Using observations and the LDAS land surface dataset, we will test a set of hypotheses that link the possible role of antecedent land surface conditions on the intensity of the NAM (Fig. 1): winter precipitation (P) leads to more winter and early spring SWE in a predictor area in the Southwest, hence more spring and early summer soil moisture (Sm) is expected, as well as lower spring and early summer surface air temperature (Ts); these conditions would feed back to the atmosphere and induce a weaker onset (and less rainfall) of the NAM and vice versa. Sections 2 and 3 describe the data and methodology utilized. In sections 4 and 5, we identify the possible winter or spring precipitation and spring snowpack predictor regions linked to monsoon precipitation and we determine their dynamical links. Based on these relationships, in section 6 we hypothesize that there is a land surface feedback mechanism associated with NAM rainfall and examine three links in this feedback chain using the LDAS-derived products (e.g., SM, SWE). In this section, we begin by testing the winter precipitation-spring snow cover-spring soil moisture hypothesis. In section 7, we demonstrate that our spring soil moisture-late spring surface temperature hypothesis is not viable. In section 8 , we conduct a preliminary analysis of the possible role of the atmospheric circulation anomalies in regulating the premonsoon land surface temperature conditions, which in turn modulate monsoon rainfall. Our conclusions are summarized in section 9.

\section{Data}

The primary source of land surface data is the retrospective LDAS dataset of Maurer et al. (2002). Monthly $\mathrm{P}$ and 2-m Ts in this dataset are gridded from climatological (daily) observations of precipitation and maximum and minimum daily temperature, from some 12000 National Climatic Data Center (NCDC) cooperative observer stations over the continental United States for the period from 1950 to mid-2000. The gridding was performed using the synergraphic mapping system (SYMAP) algorithm of Shepard (1984) as described in Maurer et al. (2002), to the $1 / 8^{\circ}$ latitude $X$ longitude LDAS grid. For precipitation, the long-term means of the gridded data were adjusted to match the Parameter-elevation Regressions on Independent

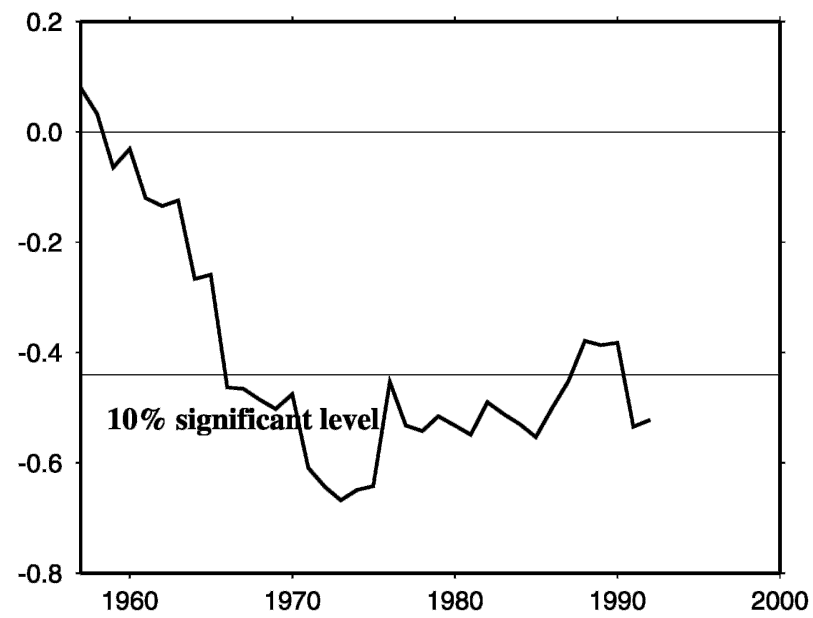

FIG. 6. The 15-yr moving correlation of JJAS monsoon precipitation vs related winter precipitation index for MW. 


\section{a) JFM}

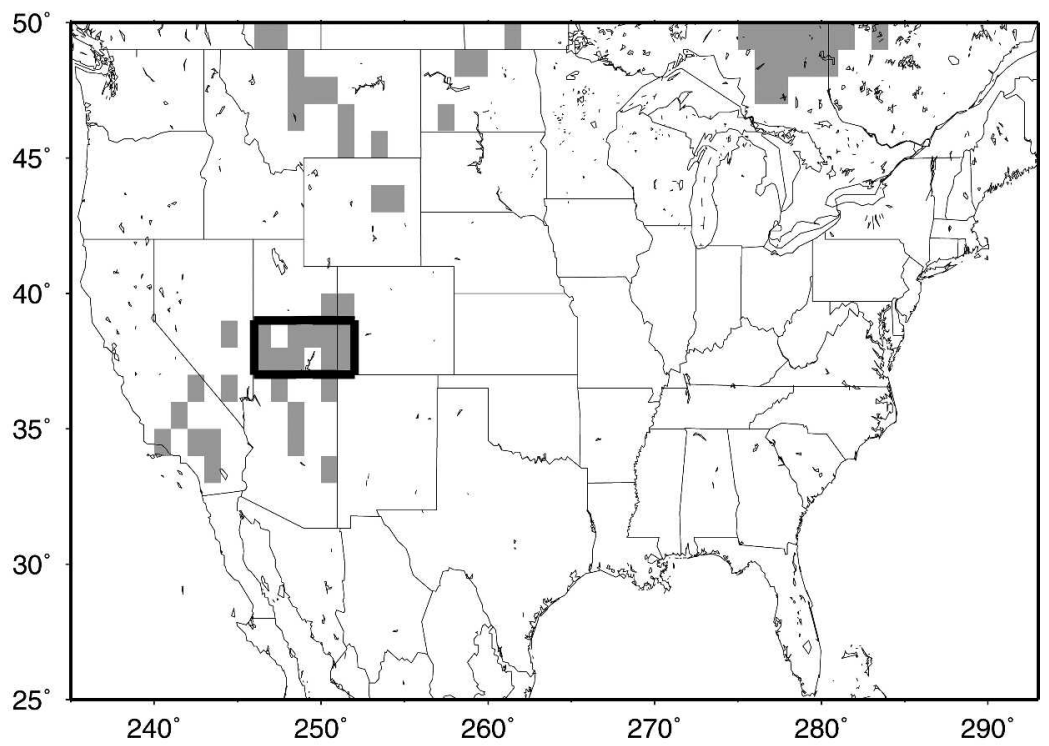

\section{b) April}

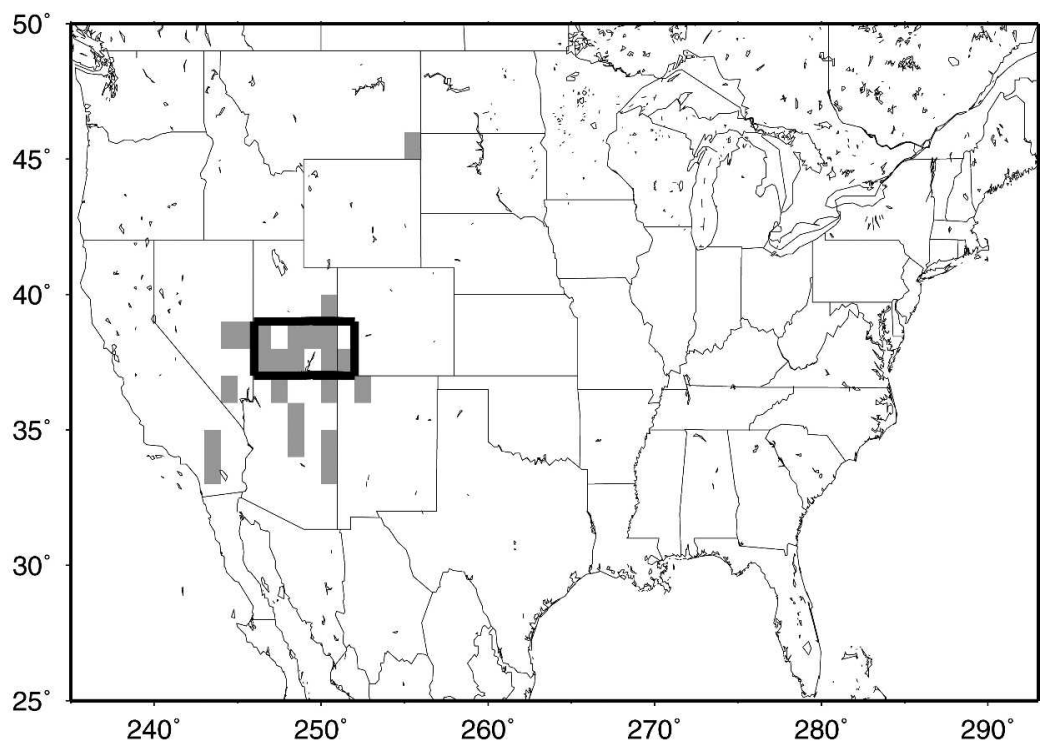

FIG. 7. Correlation of the MW JJAS monsoon precipitation vs antecedent (a) JFM, (b) Apr SWE in the entire domain during 1965-99. Significant correlations at the 5\% level $(<-0.33)$ or greater are shaded. The region in the box is defined as the MW snow index region.

Slopes Model (PRISM) of Daly et al. (1994), and Ts was lapsed to the grid cell mean elevation. Total column Sm and SWE are derived from the VIC land surface model (Liang et al. 1994). VIC is a macroscale hydrology model designed both for offline, or standalone use to simulate the water and energy budgets of large areas (e.g., large continental river basins, continents), and for use in coupled land-atmosphere models to simulate the role of the land surface in partitioning moisture and energy. (Detailed information about the dataset can be obtained online at http://www.ce. washington.edu/pub/HYDRO/edm/VIC_retrospective/ monthly.html.)

The land domain in this study extends from $25^{\circ}$ to $50^{\circ} \mathrm{N}$ and includes the conterminous United States, and parts of Canada and northern Mexico (Fig. 2). Prior to conducting the analysis, we aggregated the $1 / 8^{\circ}$ data into $1^{\circ}$ resolution data for ease of computation. 
To explore the relationship between midtropospheric conditions and surface land conditions, we use monthly mean 500-mb geopotential heights (Z500) from the National Centers for Environmental Prediction (NCEP)NCAR reanalysis data provided by the National Oceanic and Atmospheric Administration-Cooperative Institute for Research in Environmental Sciences (NOAA-CIRES) Climate Diagnostics Center, Boulder, Colorado, via their Web site (http://www.cdc.noaa. gov/). This global Z500 dataset covers the period 19482003 and has a horizontal resolution of $2.5^{\circ}$ latitude $\times$ $2.5^{\circ}$ longitude. In this paper, we defined a study domain for Z500 analysis as $10^{\circ}-50^{\circ} \mathrm{N}, 67.5^{\circ}-135^{\circ} \mathrm{W}$ covering the land domain (Fig. 2) and the adjacent ocean region.

\section{Methodology}

We use four monsoon subregions (Fig. 2) as determined by Comrie and Glenn's (1998) monsoon classification for the 1961-90 period. Comrie and Glenn regionalized the NAM region by applying principal components analysis with oblique rotation of the precipitation correlation matrix to remove the effect of elevations. Using their notation, there are four major monsoon subregions in the SW and northwestern Mexico: Monsoon South (MS), Monsoon West (MW), Monsoon North (MN), and Monsoon East (ME; Fig. 2). The MS lies in northwestern Mexico. Both MW and ME straddle the international border and lie to the west and east of Continental Divide. The MN covers northeastern New Mexico. The four monsoon regions correspond to Matsui et al.'s (2003) monsoon region. The long-term area-averaged monthly precipitation (195099) of the four monsoon regions is shown in Fig. 3. Precipitation in MS is characterized by a premonsoon dry period; the onset of the monsoon occurs in June and rainfall peaks in July-August, and decays in September. The MN receives precipitation year-round, but the largest precipitation occurs in July and August. The ME receives some rainfall in May and June, but it peaks in July, August, and September. The MW, which covers parts of Arizona and New Mexico, receives about 40\% of its annual rainfall in winter; and has a warm season precipitation peak in July-August, and as in MS, monsoon rainfall decays in September. The MW is approximately the same domain as the one used by $\mathrm{Hu}$ and Feng (2002) and Higgins et al. (1997), and exhibits a "pure" monsoonal signal. In this analysis, we focus on the role of antecedent land surface conditions on the monsoon rainfall variability of MW. In a subsequent study we will investigate the other monsoon subregions.

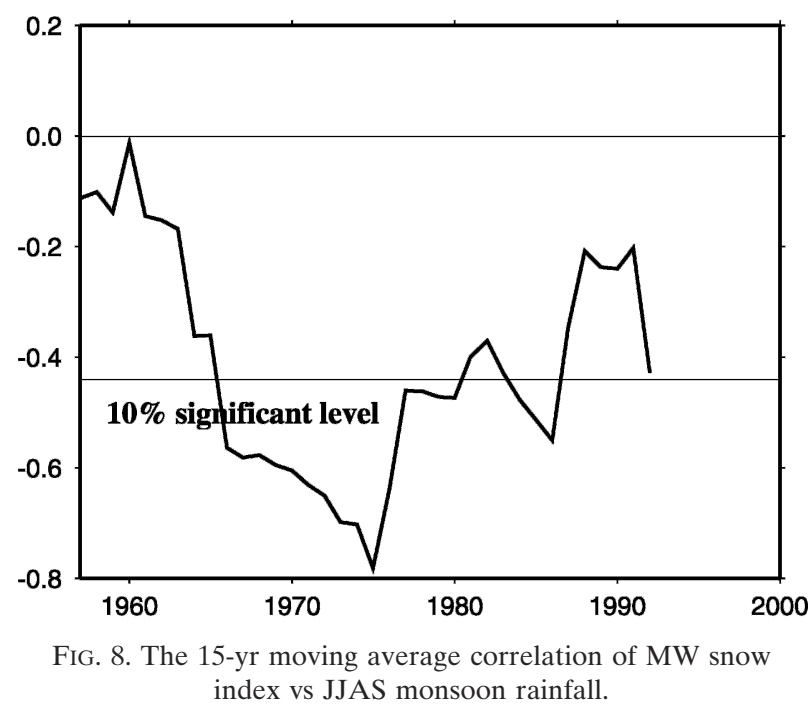

We created seasonal indices of area-averaged total JJAS precipitation for MW as the starting point for our analysis (shown later in Fig. 9). Antecedent autumn is defined as the previous October-November-December (OND), winter as January-February-March (JFM), and spring as April-May (AM). We also utilized mean monthly values of Ts, Sm, SWE, and Z500 for all the grid points of the domain. We use simple and lag correlations, sliding correlations, and composite analyses to examine the relationship between monsoon (JJAS) rainfall and antecedent autumn, winter, and spring $P$, Ts, Sm, SWE, and Z500. The Student's $t$ test is used to test the significance of spatial correlations, assuming one degree of freedom per year. Results for antecedent autumn conditions were generally not statistically significant, and thus they are not presented here. Wet and dry monsoon years for each monsoon region are defined as those years with rainfall above 1 standard deviation and below -1 standard deviation, respectively.

\section{Winter precipitation indices}

Based on past works, a promising predictor of monsoon precipitation is antecedent winter precipitation. Higgins et al. (1998) and Hu and Feng (2002) have documented that there is an inverse (positive) relationship between SW (Pacific Northwest) antecedent winter precipitation and monsoon precipitation in MW. Before constructing a winter precipitation-related index, we computed 15 -yr sliding correlations to identify areas and periods for which winter gridpoint precipitation in the domain showed the strongest correlations with JJAS precipitation in MW. Since we have only 50 yr of data, we used 15-yr sliding correlations to avoid losing too many points at the end of the time series. The 


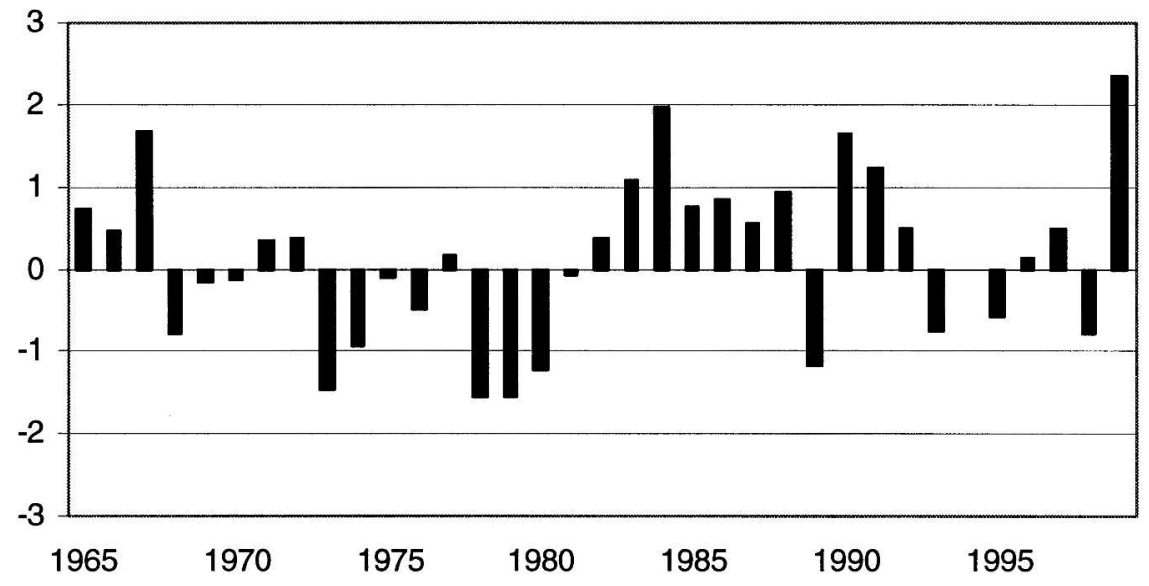

FIG. 9. Standardized anomalies of JJAS precipitation in the MW.

longest period (1965-99) and areas for which the correlation was significant is shown in Fig. 4. The winter precipitation-correlated area for MW (Fig. 4) is consistent with the results of Higgins et al. (1998, see their Fig. 19) and Hu and Feng (2002). However, the Pacific Northwest signal documented by Higgins et al. is not persistent in time; thus, our winter precipitation index is based only on the inverse (negative correlation) link found in the Southwest (California, Nevada, Arizona, Utah, and parts of New Mexico and Colorado; Fig. 4). Since this region covers high elevations of the Rocky Mountains, we expect a link between spring snowpack (related to winter precipitation) and summer rainfall in MW as suggested by Gutzler and Preston (1997) and Gutzler (2000). Figure 5 shows the winter (JFM) precipitation index time series. It seems that at the end of the 1970 s there was a shift to larger winter precipitation totals, possibly associated with North Pacific decadal fluctuations (e.g., Dettinger et al. 1998; Gershunov and Barnett 1998; Gershunov and Cayan 2003).

The 15-yr moving correlations between the winter precipitation index and MW rainfall is shown in Fig. 6; the strongest correlation is observed from 1965 to the 1990 s, in agreement with the results of $\mathrm{Hu}$ and Feng (2002) for precipitation, and with Gutzler (2000) for snow cover. Lo and Clark (2002) also found that the characteristics of the relationship between SWE and NAM rainfall vary through time. This suggests that we need to be careful with the temporal links and associations when formulating a predictive model.

\section{Snow-monsoon connection}

Gutzler and Preston (1997) and Gutzler (2000) showed that there is a negative feedback between snow (wet-clim.)/clim.

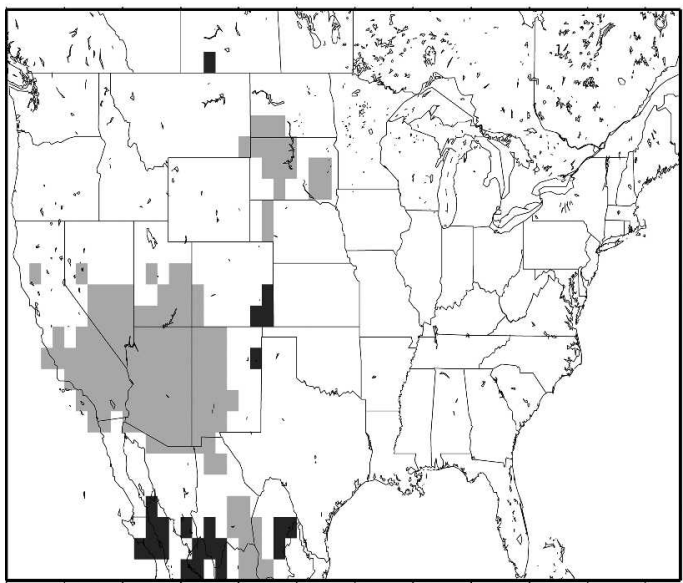

(dry-clim.)/clim.

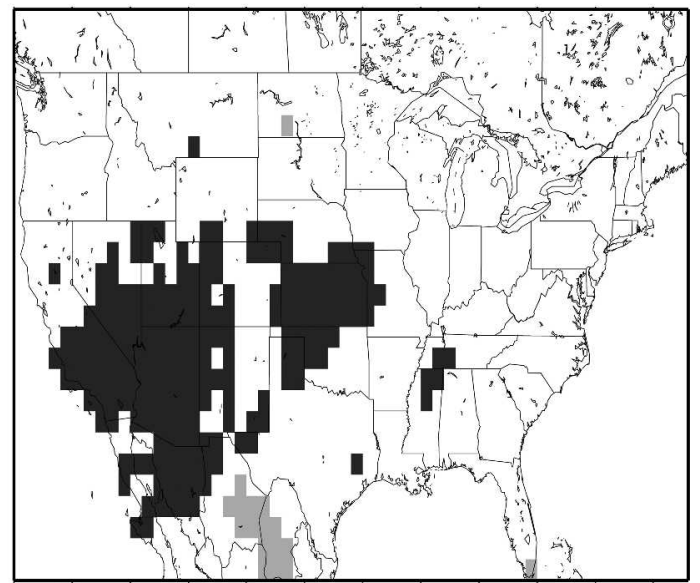

FIG. 10. The MW JFM relative precipitation anomaly composite for wet and dry monsoon years during 1965-99. Shaded area is $\geq 0.25$ (dark) or $\leq-0.25$ (gray). 
a) $\mathrm{AM}$

wet-clim.

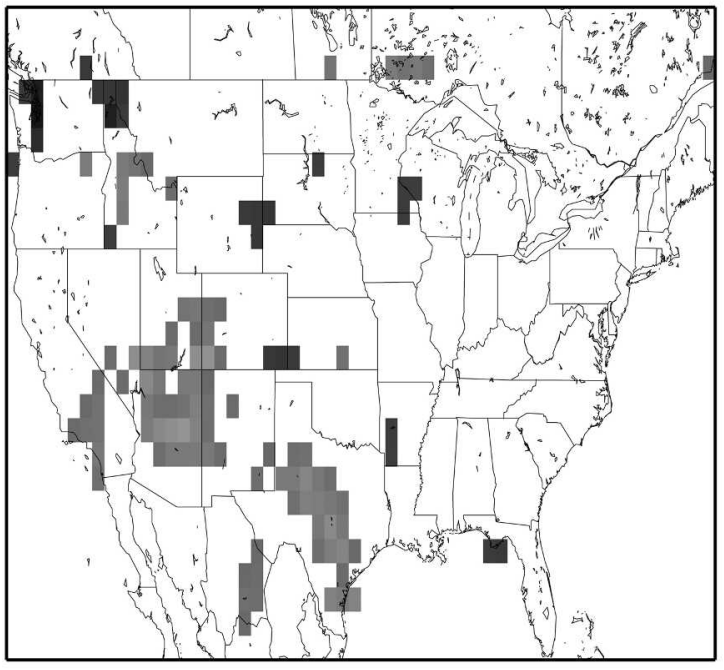

dry-clim.

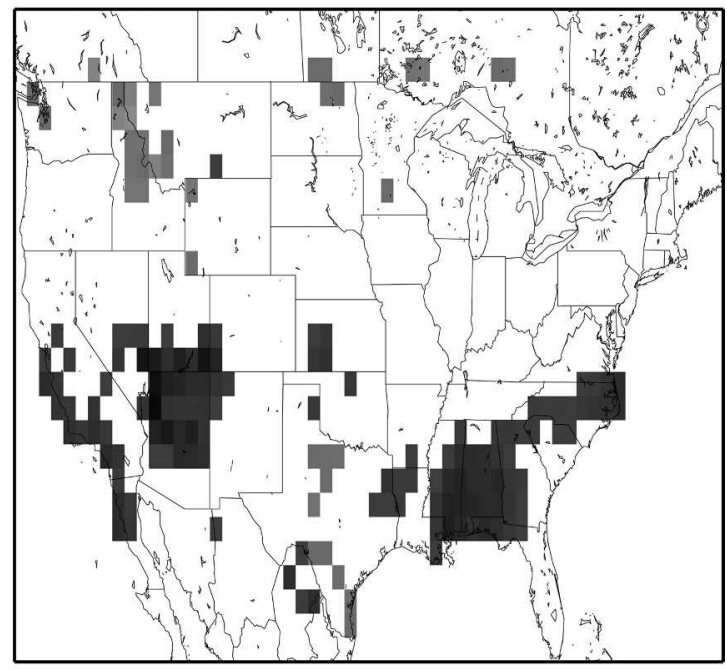

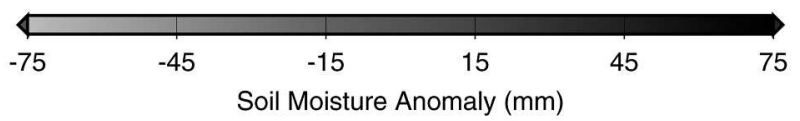

b) June

wet-clim.

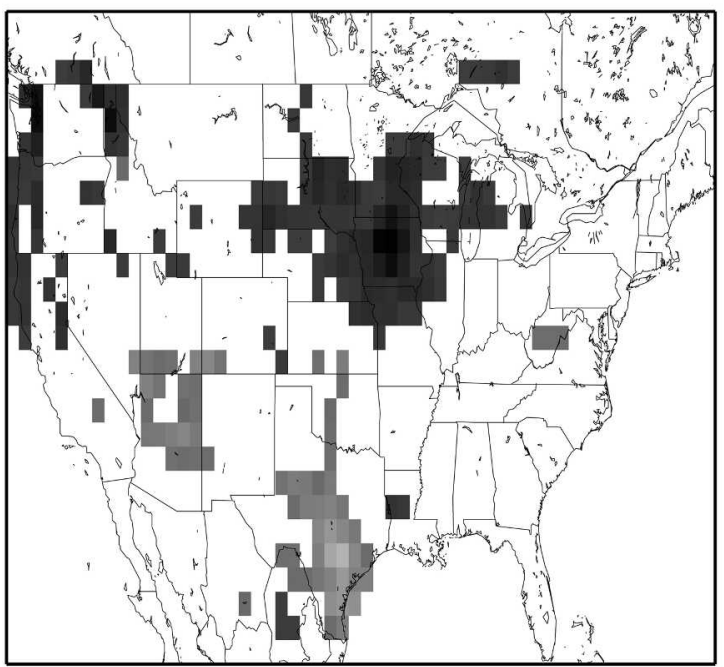

dry-clim.

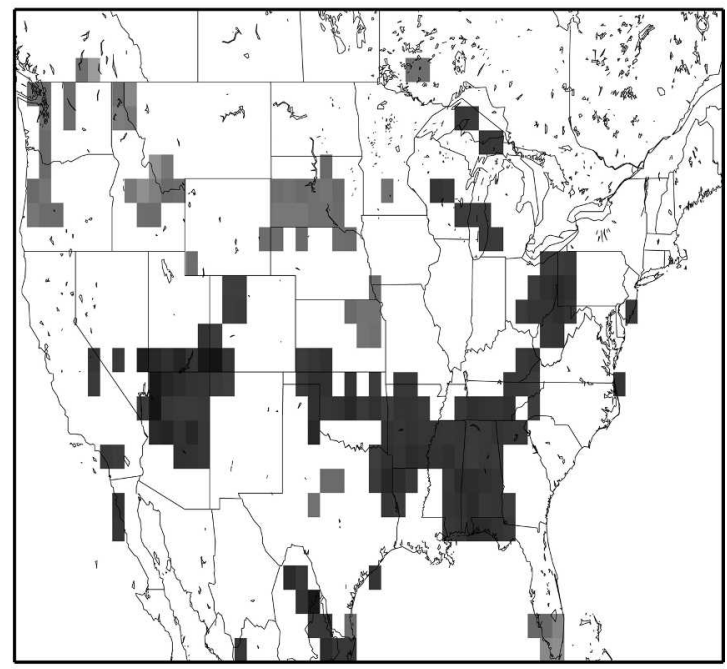

45

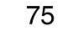

FIG. 11. The MW soil moisture anomalies during wet and dry monsoon years for (a) AM (Apr-May) and (b) Jun during $1965-99$. Shaded area is $\geq 20 \mathrm{~mm}$ (dark) or $\leq-20 \mathrm{~mm}$ (gray).

cover in the mountainous areas of the western United States and summer monsoon rainfall, and that this relationship is stronger from 1960 to 1990. This snowmonsoon feedback could be nonlocal because the win- ter snow accumulation area is not necessarily located in the same region as the monsoon rainfall response area (Barnett et al. 1989). As for our winter precipitation analysis, we utilized a 15-yr sliding correlation of JFM 
and April SWE and JJAS monsoon rainfall to find the area for which there is a significant correlation between MW precipitation and winter and spring SWE. During JFM and April, the southern Rocky Mountain area shows a statistically significant inverse relationship with monsoon rainfall, as shown in Fig. 7. The Great Lakes area of Canada also shows an inverse relationship, but only in JFM. Based on these results, we defined a common area in the southern Rocky Mountains for determining the relationship between JFM and April SWE and MW precipitation (box in Fig. 7). The 15-yr moving correlation indicates that the most significant inverse relationship between monsoon rainfall and SWE in the southern Rocky Mountain is during the period from 1965 to the mid-1980s (Fig. 8). The snow-monsoon signal is even stronger than the Southwest winter precipitation-monsoon signal, especially in the 1970s. This suggests that snow could be a better predictor than precipitation in the SW. This finding contrasts with the results of Lo and Clark (2002) who document that the strongest snow-monsoon association occurred before the 1970s.

\section{Winter precipitation-soil moisture-monsoon rainfall feedback hypothesis}

Higgins et al. (1998) and Hu and Feng (2002) hypothesize that the inverse relationship between winter precipitation and monsoon precipitation in the SW is partly due to a land memory effect. Meehl (1994) noted that for the south Asian monsoon the soil moistureprecipitation feedback could be either positive or negative. Elevated soil moisture induces higher evaporation, which causes cooler surface temperatures, decreased land-sea temperature contrast, and a weak monsoon. Based on the concept that the NAM is initially dynamically induced by the land-sea temperature contrast, we propose that there is a winter P-Sm-Ts-NAM feedback mechanism (Fig. 1). The hypothesis for the snowmonsoon feedback mechanism is similar to that for a winter $\mathrm{P}$-monsoon feedback mechanism. Heavy winter and early spring snow leads to wetter spring soil, and cooler surface temperatures, which may cause a weak land-sea temperature contrast, and hence a weak monsoon. We begin by testing this hypothesis in the MW region during the period 1965-99, for which the apparent relationship between the previous winter's conditions is strongest. We tested this hypothesis initially on extreme wet $(>1$ std dev) and dry $(<-1$ std dev) years in the MW region. There are five wet and six dry monsoon years in the 1965-99 period, as can be seen in the standardized precipitation anomalies in Fig. 9. Figure 10 shows the winter relative precipitation composite

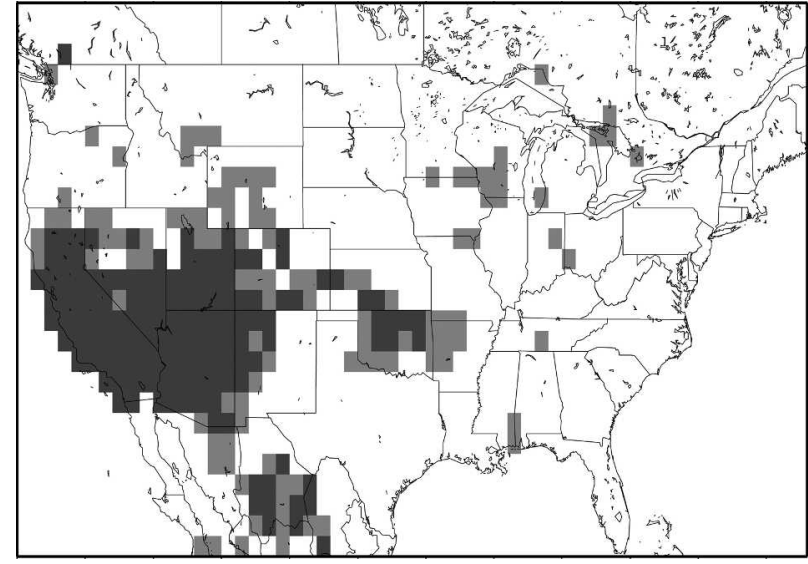

FIG. 12. Correlation of SW winter precipitation index vs Jun soil moisture over the entire domain during 1965-99. Shaded area is significant correlation at the $5 \%$ level (gray, >0.33) and 1\% (dark $>0.42$ ) level or greater.

anomaly for wet and dry monsoon years in MW. There is a strong inverse relationship between winter and summer precipitation in the SW. The signal is consistent with the correlation map shown in Fig. 4, but the link with the Pacific Northwest winter precipitation (Fig. 4) does not hold during extreme events (Fig. 10). Interestingly the precipitation signal during dry years is much stronger than during wet years and it also covers a larger area, extending into northwestern Mexico and the Great Plains. This may imply stronger predictability in dry years.

A key process for the winter $\mathrm{P}$-spring Sm-late spring Ts hypothesis is the amount of soil moisture that the soil is able to retain through the (generally dry) spring, and that in turn can exert an energy link to the atmosphere during the monsoon season. Figure 11 shows the April-May and June Sm anomaly composites for wet and dry monsoon years in MW. The spring Sm pattern (Fig. 11a) is similar to the winter precipitation pattern (Fig. 10) in the western United States (less spring Sm during wet monsoons and vice versa in the SW and the southern Rocky Mountains), implying that the land has a memory effect from winter precipitation. The spring (AM) Sm signal in the southeast United States (Fig. 11a) is strong and positive during dry monsoon years (more spring Sm), but there is not a corresponding winter precipitation signal (Fig. 10), possibly because this region receives more precipitation in spring than in winter (e.g., Mock 1996). During wet monsoon years Texas shows low spring Sm, a signature that is not evident in winter precipitation either, but it appears to have an impact on May Ts, as we will see later (Fig. 13a). Figure $11 \mathrm{~b}$ shows the $\mathrm{Sm}$ anomalies in June for wet and dry monsoons in the MW region. Low (large) 
a) May
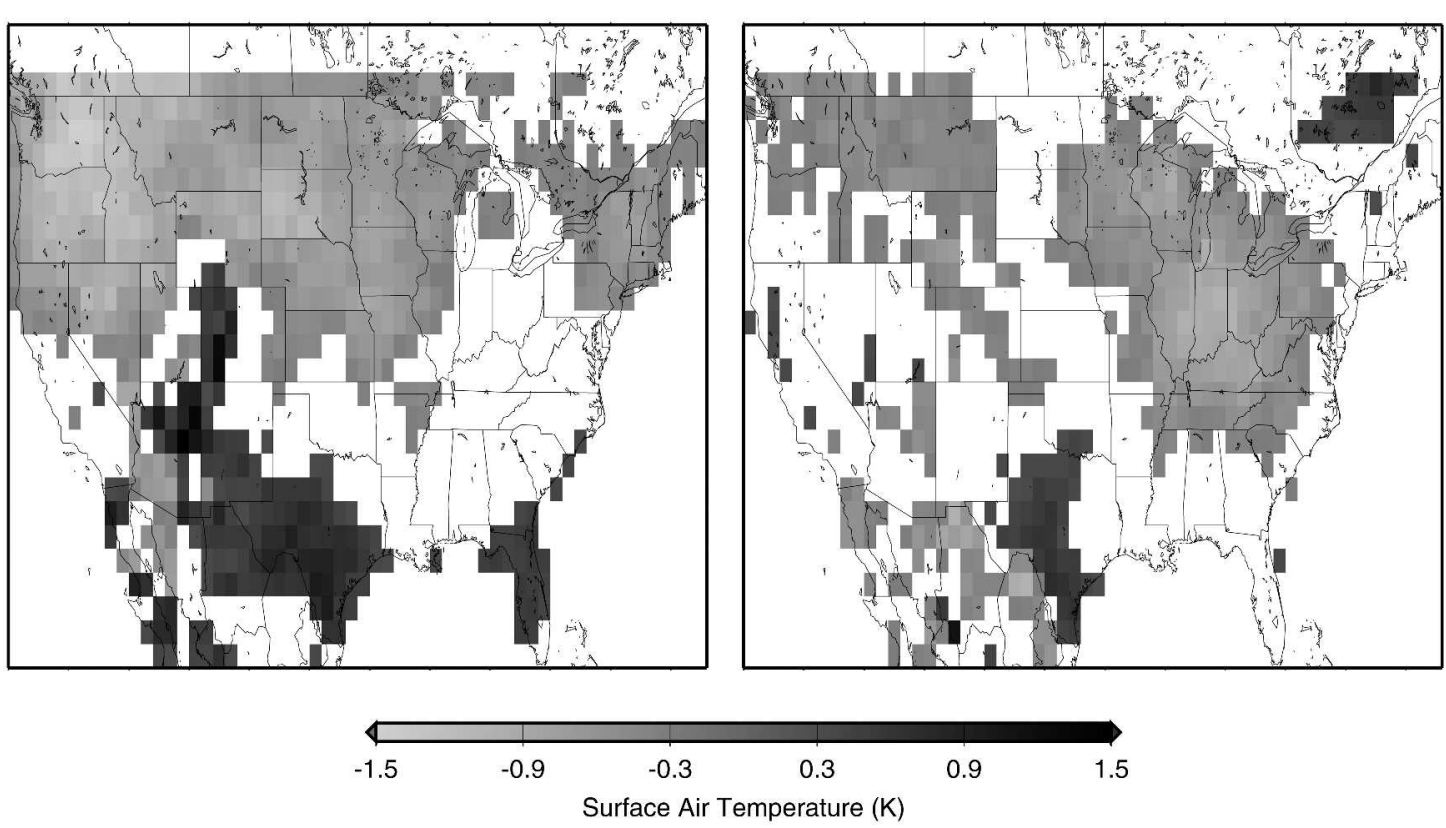

b) June

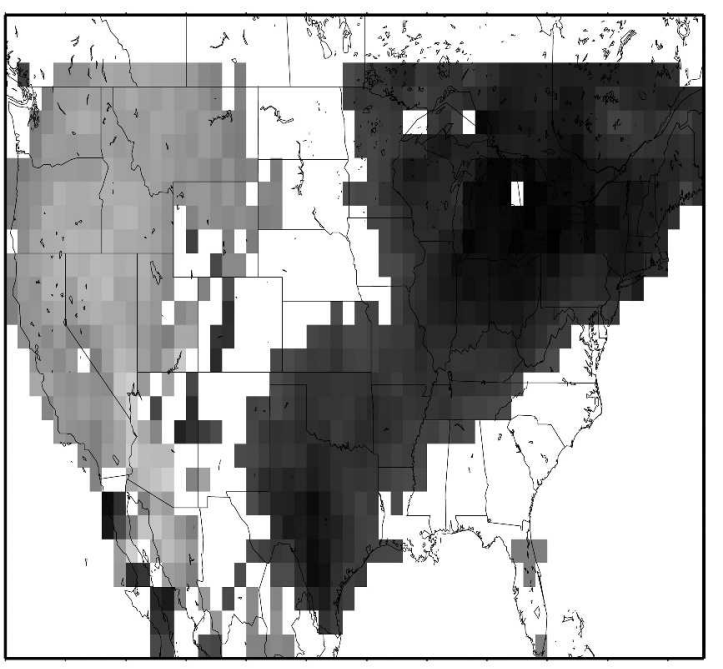

wet-clim

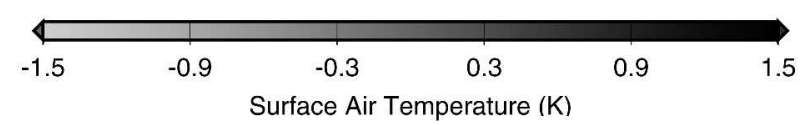

dry-clim

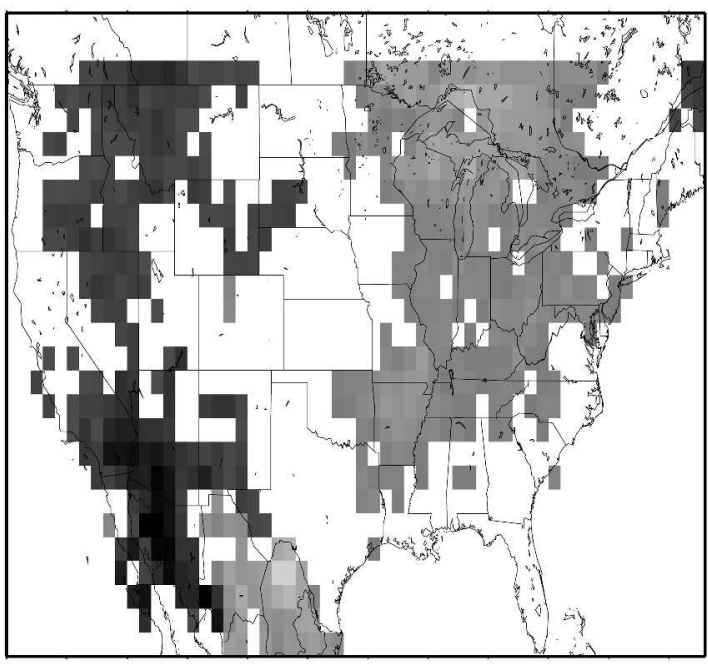

Fig. 13. The MW (a) May and (b) Jun surface air temperature anomaly maps in wet and dry monsoon years during $1965-99$. Shaded area is $\geq 0.3 \mathrm{~K}$ (dark) or $\leq-0.3 \mathrm{~K}$ (gray).

amounts of Sm in Arizona and the southern Rockies during wet (dry) monsoon years persist from spring (Fig. 11a) to June, possibly having an impact on the dynamics of the monsoon on the next month. It is interesting to see the out-of-phase relationship between
Sm in the SW and Sm in the Great Plains-Midwest. The latter region receives more rainfall in June and the SW receives more in July (e.g., Castro et al. 2001). Thus, possibly the larger amount of Sm in the Great Plains seen in wet years (and vice versa) reflects higher 

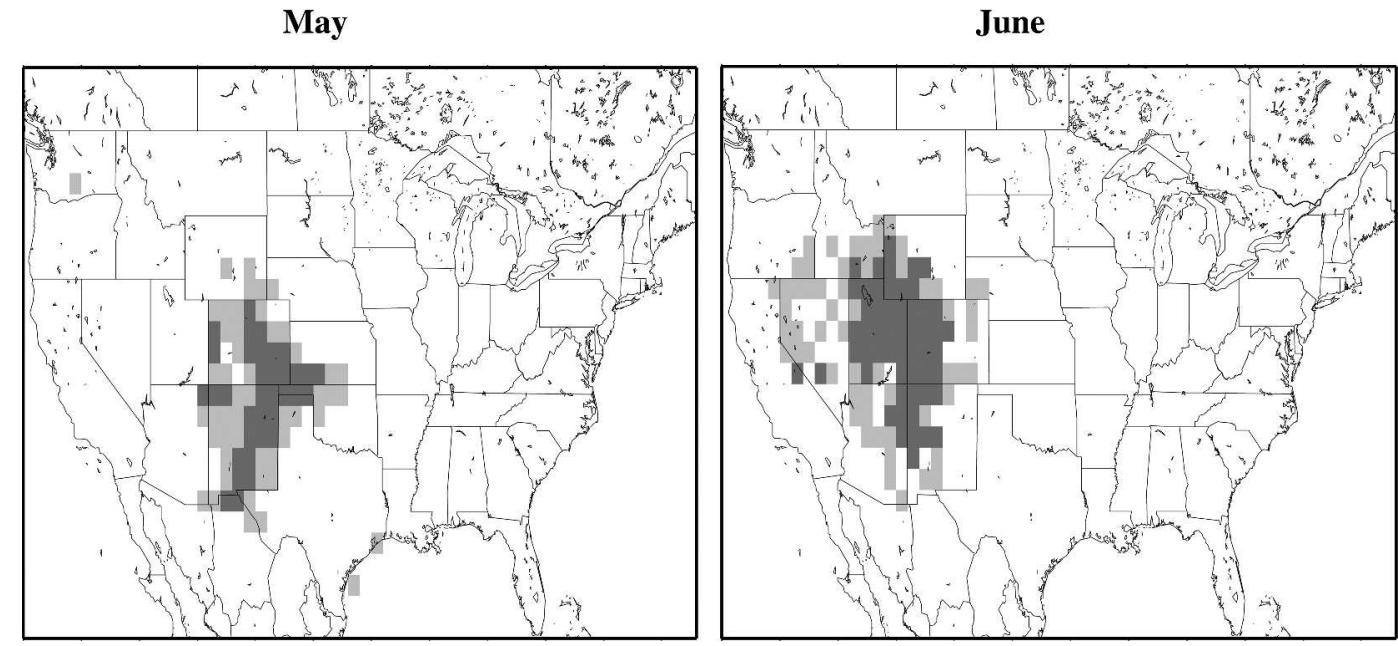

FIG. 14. Correlation of Apr SWE index vs May and Jun surface air temperature during 1965-99. Shaded area is at the $10 \%$ (gray, $<-0.28$ ) and $5 \%$ (dark gray, $<-0.33$ ) significance level or greater.

(lower) June rainfall in this region during extreme monsoon conditions. Figure 12 shows the correlation between the winter precipitation index and June Sm. There is a significant positive relationship over the entire period 1965-99, which can be interpreted as evidence that the SW has a land memory that persists from winter through late spring. Logically, the next question is whether this soil moisture anomaly plays a role on the onset and magnitude of the monsoon, a question that we explore in the next section.

\section{Spring soil moisture-late spring surface temperature feedback}

There are three links in our winter $\mathrm{P}$-spring Sm-late spring Ts-monsoon hypothesis: a positive relationship between winter $\mathrm{P}$ and spring Sm, an inverse relationship between spring Sm and late spring Ts, and a positive correlation between June Ts and monsoon precipitation. To make the pathway relating the winter precipitation to monsoon precipitation viable, each of these three links must be verified. The first link was evident through the composites and correlation analysis discussed above; now we examine the second link that wetter soil in spring yields colder surface temperature in the premonsoon month (June) in the SW and vice versa. Figure 13 shows the May and June surface temperature anomaly composite maps during wet and dry monsoon years. May and June (Fig. 13) exhibit very different Ts patterns. As hypothesized, May Ts anomalies in the SW (Fig. 13a) show an inverse relationship with spring Sm (Fig. 11a), especially during wet monsoons (i.e., less spring Sm, higher May Ts). Negative spring $\mathrm{Sm}$ anomalies are seen in the mountainous part of the SW, the southern Rocky Mountains, and Texas during wet years and are correlated with higher May Ts (with some cells $>1 \mathrm{~K}$ ). In dry monsoon years, May Ts is lower than normal in northern Mexico, as well as in the mountainous part of the SW and the southern Rockies. This suggests that the southern Rocky Mountain snow cover could be a key factor influencing Ts in the SW mountainous region in late spring (explicitly shown by the negative correlations in Fig. 14). The possible reason is that the heavy snow may delay the heating of the continent by increased albedo and by creating an energy sink for melting snow. However, during wet (dry) monsoon years, this negative snow-Ts relationship disappears in June as indicated by the negative (positive) Ts anomalies in Fig. 13b. This further suggests that there are other factors influencing June surface air temperature and, in extreme years, they appear to be strong enough to mask the role of spring snow.

Figure 13b shows that surprisingly, the positive May Ts anomaly seen in the SW during wet monsoons weakens by June and strong negative anomalies take over in northwestern Mexico, Arizona, and the southern Rockies. The opposite occurs during dry monsoons. The June anomaly map (Fig. 13b) shows an interesting symmetric pattern between the western and the eastern half of the domain, with the eastern (western) part showing a positive (negative) anomaly signal in wet years and visa versa for dry years. The Ts anomalies seen in May (Fig. 13a) change to a strong east-west anomaly pattern in June, possibly reflecting the influence of late spring and early summer large-scale circulation (shown later in Fig. 19). The apparently inconsistent patterns of June Sm (Fig. 11b) and June Ts (Fig. 13b) basically contra- 


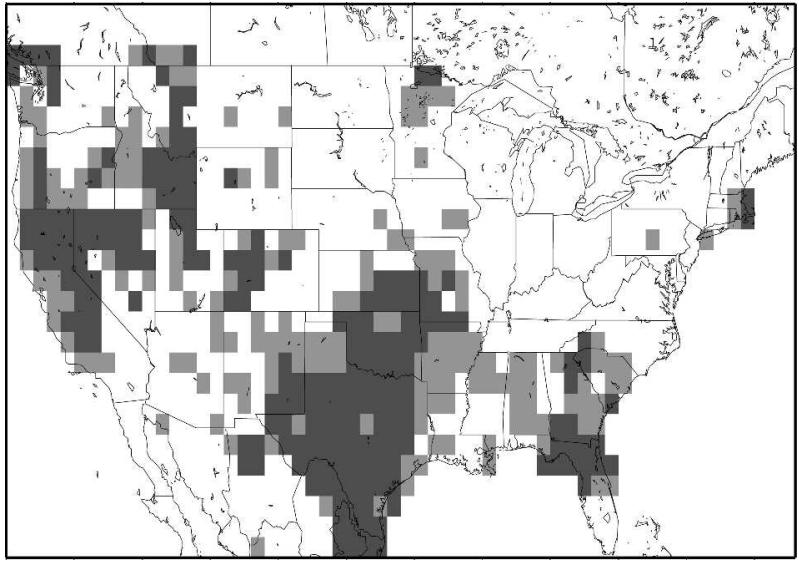

FIG. 15. Correlation of Jun soil moisture vs Jun surface air temperature over the entire domain during 1965-99. Shaded area is significant correlations at the $5 \%$ (gray, $<-0.33$ ) and $1 \%$ (dark gray, $<-0.42$ ) level or greater.

dict the existence of the proposed spring Sm-late spring Ts negative link in the monsoon region.

The correlation map between June Sm and June Ts (Fig. 15) further supports the absence of a relationship between these two variables in most of the SW and in northwestern Mexico. One reason may be the small evapotranspiration signal in this semiarid area (Fig. 16), the sparse vegetation in the SW does not favor much extraction of soil water from the deep soils where most of the moisture is stored. The long-term mean June evaporation spatial distribution (Fig. 16) exhibits a somewhat consistent pattern with the June Sm and June Ts correlation map (Fig. 15) and with Tmax (not shown here, Ts and Tmax are positively correlated, $>0.7$ ) in most of the domain. Larger evaporation is associated with cooler surface temperatures and vice versa, but the signal is weak in the SW. The broken Sm-Ts link implies that local premonsoon June soil moisture conditions and evaporation in the SW do not play a significant role in the strength of the monsoon. While snow is an important land surface variable that affects late spring Ts in the SW mountainous region (Fig. 14), it does not appear to do so through soil moisture because the second link in our hypothesis breaks down.

To further evaluate the robustness of the land surface mechanism associated with the monsoon, we test the

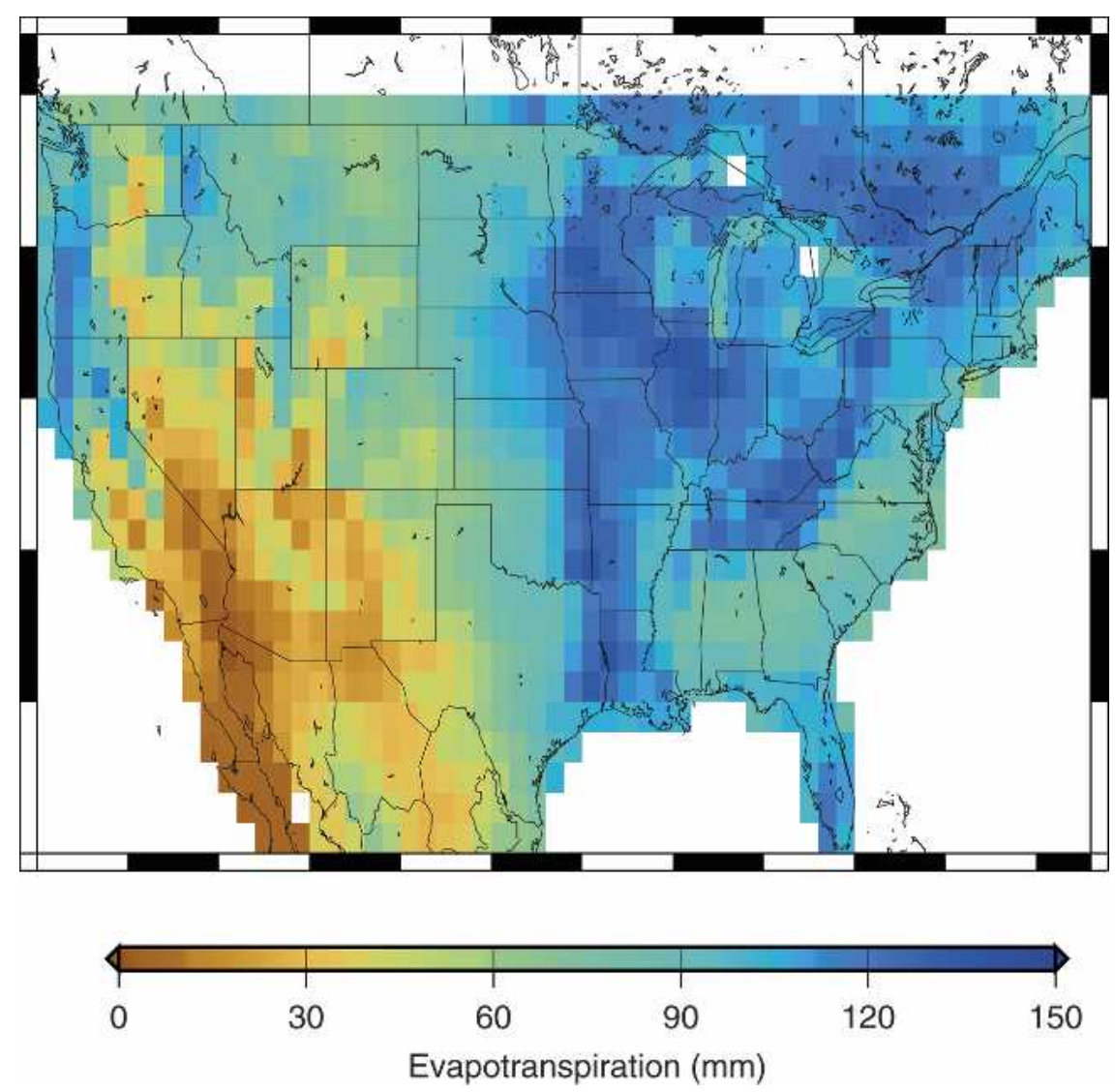

FIG. 16. The long-term mean evaporation during 1965-99. 

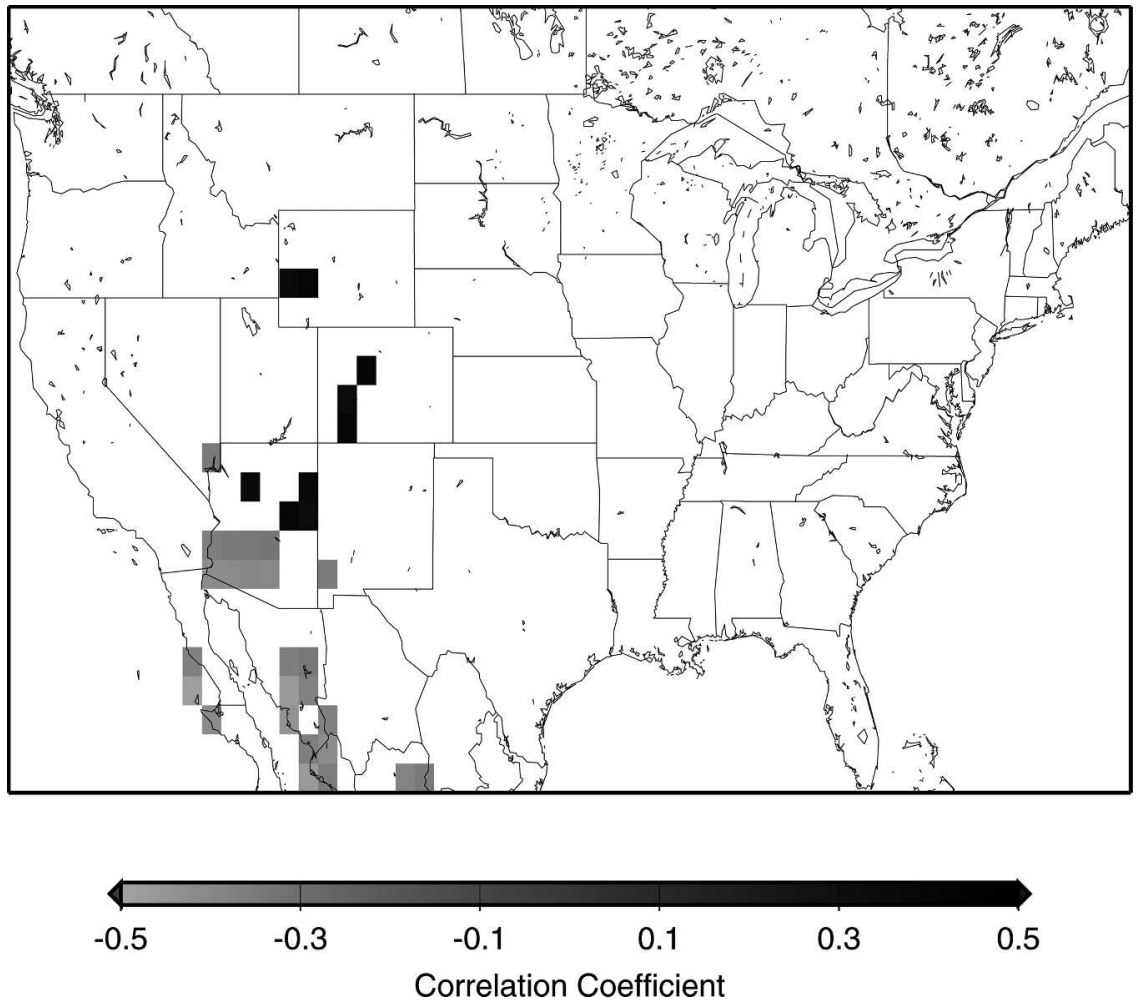

FIG. 17. Correlation of Jun surface air temperature vs Jul MW precipitation during 1965-99. Shaded area is at the 5\% significance level or greater.

third link (Ts-monsoon) in our hypothesis. Figure 17 shows the correlation between June Ts and July MW precipitation. Only a few cells in the SW mountainous region show a statistically significant (positive) relationship consistent with the Ts composite maps during extreme monsoons (Fig. 13b). Statistically this is consistent with the fact that June Ts and monsoon P in these cells are negatively correlated with spring snow cover (Figs. 7 and 14). On the contrary, the SW desert area and parts of Northwestern Mexico exhibit a negative correlation between June Ts and July P, the opposite of what we expect based on the monsoon driving force concept of the land-sea thermal contrasts.

Early summertime land surface extreme heating in the Southwest-especially in the lower elevationsproduces a surface thermal low centered over the desert regions of southern Arizona and southeastern California (Carleton 1985; Rowson and Colucci 1992). The resultant pressure gradient around the SW and adjacent ocean provides the driving force for the moisture drawn northward to the heated land from the Gulf of California hence the onset of the monsoon season (Hales 1974). However Figs. 13b and 17 indicate that there is a weak or even reverse signal between June Ts in MW and the magnitude of MW monsoon precipitation. One might question whether this inverse relationship could be caused by an earlier arrival of the monsoon in June (especially in the Mexican core of the monsoon) because once the rains start the relationship between Ts and $\mathrm{P}$ changes.

Figure 18 shows the SW desert area daily precipitation (JJ) in extreme years. The rains arrive in early July during wet years, hence the inverse relationship between June Ts and monsoon $\mathrm{P}$ shown in Figs. 13b and 17 in SW is not related to the earlier arrival of monsoon precipitation. Overall, the lack of a significant Sm-Ts- $P$ relationship in most of our study area suggests that the local premonsoon land surface conditions such as soil moisture do not play an obvious role on the magnitude of the monsoon, at least not in the way we hypothesized based on our derived LDAS soil moisture data. Snow has some influence on premonsoon Ts in the SW high elevation areas (Fig. 14), but not during extreme years; and the role of soil wetness on Ts seems to be small. Thus, we hypothesize that premonsoon Ts is linked instead to a large-scale forcing mechanism that may further modulate the strength of monsoon rainfall. 

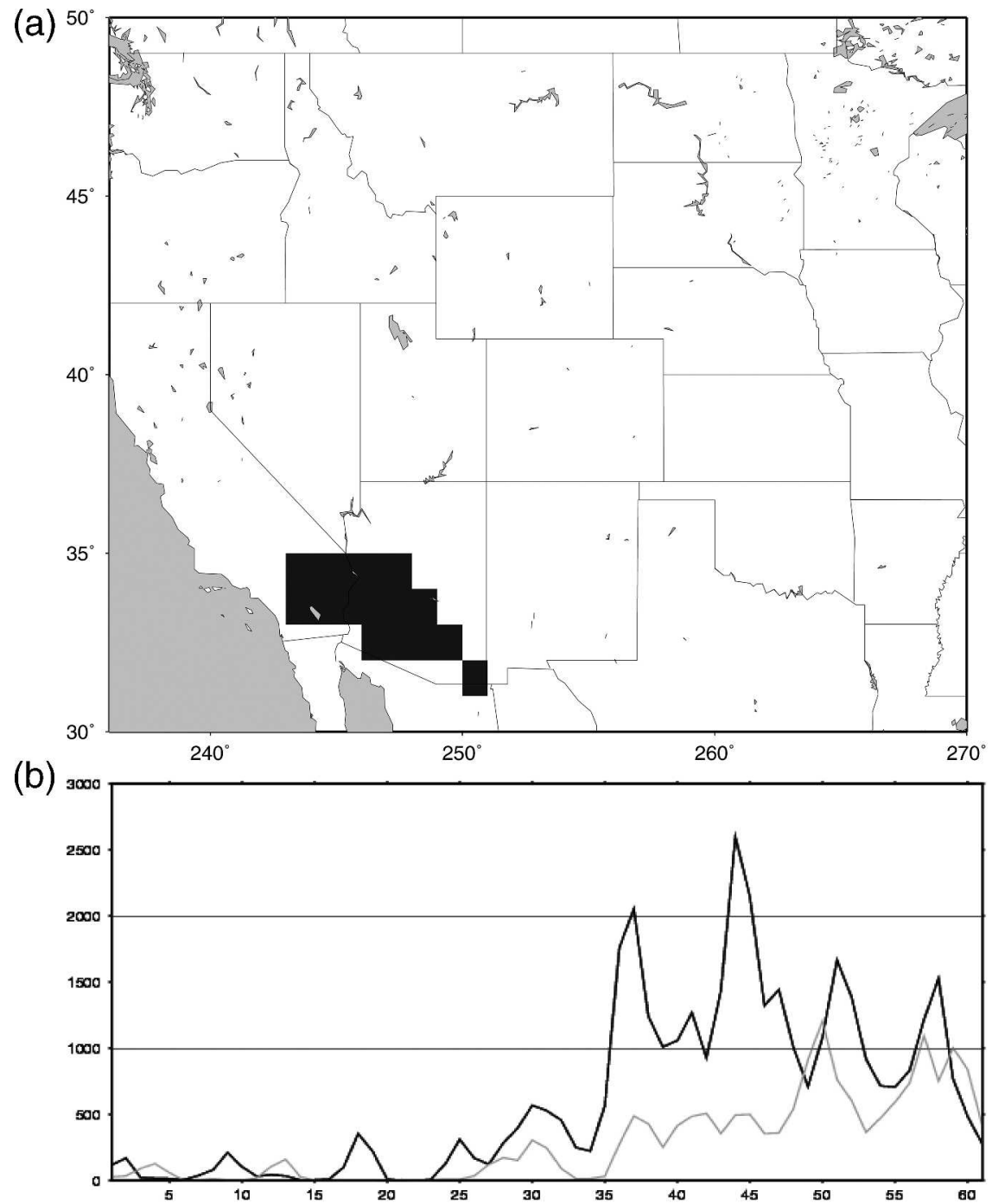

FIG. 18. (a) SW desert region and (b) mean daily Jun-Jul Southwest desert area total precipitation (mm) during wet (dark) and dry (gray) monsoon years during 1965-99.

\section{Role of upper-troposphere circulation}

Figure 19 displays the $500-\mathrm{mb}$ geopotential height (Z500) anomaly composite maps in extreme years for JFM and June. During wet (dry) monsoons the winter circulation is characterized by positive (negative) geopotential height anomalies, which are linked to dry (wet) winter conditions in the SW (Fig. 4), as has been documented previously (e.g., Higgins and Shi 2000). The June Z500 anomaly map exhibits a strong low-high pattern during wet monsoons (Fig. 19a) distributed symmetrically between the western and eastern sides of North America similar to the June surface air temperature anomalies shown in Fig. 13b. The opposite occurs during dry monsoons (Fig. 19b) when positive Z500 anomalies dominate the SW. These results indicate a strong positive relationship between June Ts and the large-scale midtropospheric circulation before the onset of the monsoon (the higher Z500 in June in the SW induces warmer surface temperature in dry years, and the reverse for wet years), suggesting that the controlling factor for the premonsoon surface air temperature anomalies may not be local (i.e., related to land surface conditions), at least in extreme years.

\section{Summary and conclusions}

We have used observed precipitation and derived soil moisture and snow extent from the LDAS land surface dataset (Maurer et al. 2002) to test a simple set of hypotheses that link the role of antecedent land surface 
a) Wet
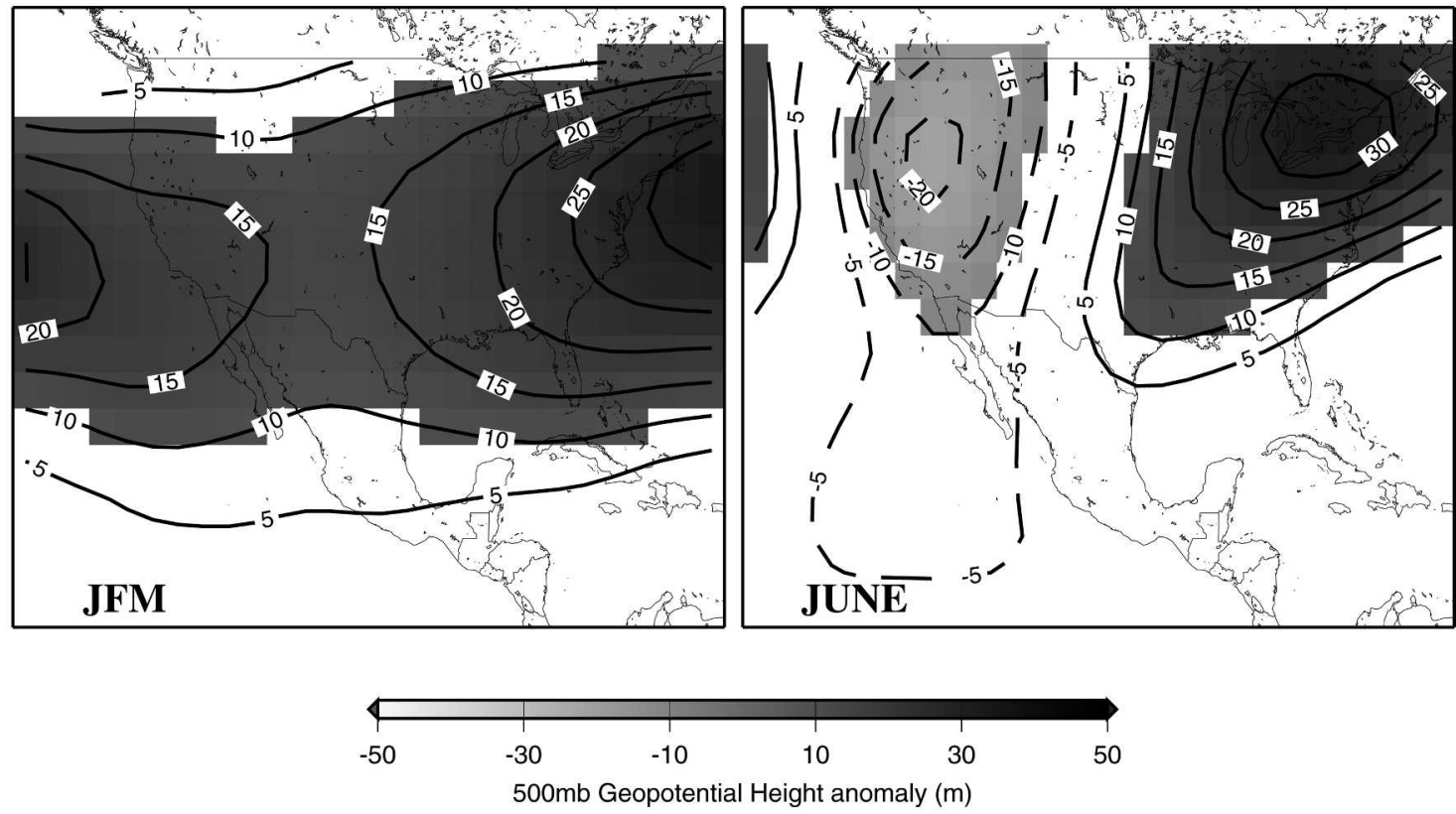

b) Dry
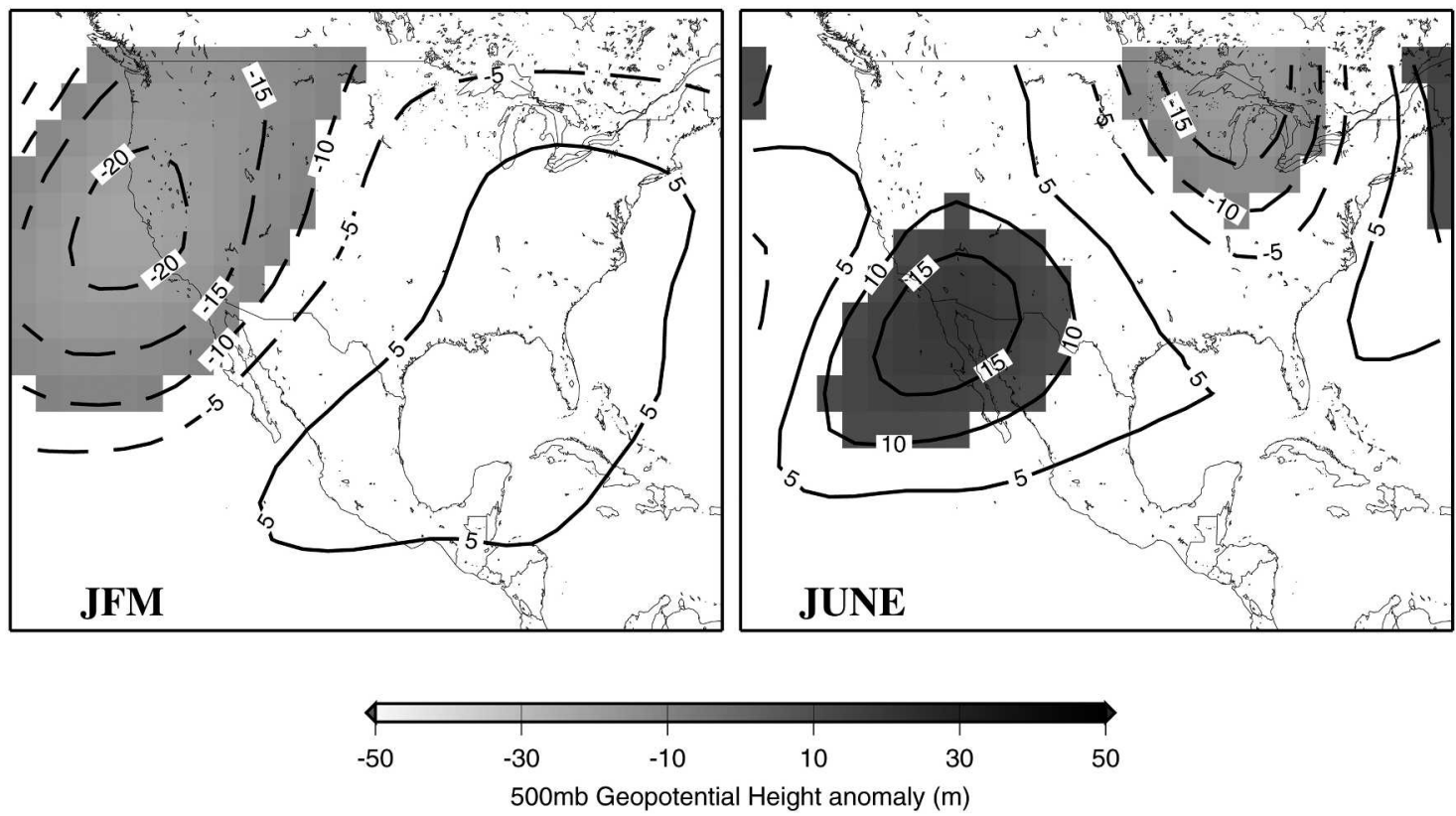

FIG. 19. Winter (JFM) and Jun 500-mb geopotential height (Z500) anomaly maps in (a) wet and (b) dry monsoon years during 1965-99. Shaded area is $\geq 10 \mathrm{~m}$ (dark) or $\leq-10 \mathrm{~m}$ (gray).

conditions on the intensity of the NAM (Fig. 1) precipitation in the Monsoon West (MW) subregion, which includes parts of Arizona and New Mexico. We evaluated the possible effects of antecedent land surface conditions in various subcontinental "predictor regions" linked to MW precipitation. Based on previous studies (Gutzler and Preston 1997; Higgins et al. 1998; Gutzler 2000; Hu and Feng 2002), we determined two winter precipitation $(\mathrm{P})$ and snow water equivalent (SWE) predictor regions, which have strong linkages with summer monsoon rainfall anomalies in MW. We found, as have other authors, that relationships be- 
tween the previous winter's land surface condition $(P$ and SWE) and the subsequent summer's monsoon strength are not stable in time. For instance, we found a statistically significant negative correlation between winter (JFM) precipitation in the SW predictor region (southern California, Nevada, Utah, Arizona, western Colorado, and New Mexico) and MW monsoon rainfall during the 1965-90 period, but weak relationships for other periods. We also found negative correlations between MW precipitation and winter-spring SWE in a predictor region that includes the mountainous portions of SW. These relationships were especially strong between 1965 and the late 1980s. Based on the concept that the onset of the NAM is dynamically induced by land-sea temperature contrasts, we hypothesize that for MW, more winter P leads to more winter and early spring SWE in the predictor area, hence more spring and early summer Sm, and lower spring and early summer Ts, which induces a weaker onset (and less rainfall) of the NAMS and vice versa. We tested all of the three links in this land surface feedback hypothesis. First, we found that spring SW soil moisture has a memory from the previous winter, and that this memory can persist through April, May, and June. However, this soil wetness memory contributes little to the magnitude of NAM precipitation in MW. Snow negatively affects SW mountain region late spring Ts, but not through the soil moisture link, and this negative relationship disappears in extreme years. In particular, the premonsoon (June) Ts over the SW desert is inversely related with monsoon precipitation, which is the reverse of what we expect based on the monsoon driving force concept of land-sea temperature contrasts. We developed an alternate (to Fig. 1) hypothesis that the onset of the monsoon is linked to a large-scale forcing mechanism and that the land surface conditions, such as local soil moisture and evaporation, may play a significant role after the onset, but not before in our study area. We found a strong positive relationship between June Ts anomalies and the large-scale midtropospheric circulation (Z500) anomalies before the onset of the monsoon, suggesting that premonsoon Ts anomalies are not modulated by the local land surface conditions in the SW.

While our analysis does not support a straightforward link between antecedent land surface conditions, we do no rule out the possibility that land surface conditions could affect monsoon strength in other, more complicated ways. There remain many other factors and mechanisms that need to be investigated to get further insight into this puzzle. Among these are the role of SST anomalies in the premonsoon Ts-monsoon relationship, interactions of atmospheric circulation and surface temperature, and the possibility of the dif- ferent feedback mechanisms in extreme years and normal years. Furthermore, in this study we focused on MW precipitation, but eventually, we expect to evaluate the land-sea-atmosphere feedbacks (or absence thereof) in all the North American monsoon regions (United States and Mexico) and to obtain a more complete understanding by extending the time period of the LDAS dataset to include most of the twentieth century and all of Mexico.

Acknowledgments. This publication was funded by the Joint Institute for the Study of the Atmosphere and Ocean (JISAO) under NOAA Cooperative Agreement NA67RJ0155. It was also partially funded by UCMexus-CONACyT to the third author.

\section{REFERENCES}

Abdulla, F. A., D. P. Lettenmaier, E. F. Wood, and J. A. Smith, 1996: Application of a macroscale hydrologic model to estimate the water balance of the Arkansas-Red River basin. $J$. Geophys. Res., 101, 7449-7459.

Adams, D. K., and A. C. Comrie, 1997: The North American monsoon. Bull. Amer. Meteor. Soc., 78, 2197-2213.

Bamzai, A. S., and J. Shukla, 1999: Relationship between Eurasian snow cover, snow depth, and the Indian summer monsoon: An observational study. J. Climate, 12, 3117-3131.

Barnett, T. P., L. Dumenil, U. Schlese, E. Roeckner, and M. Latif, 1989: The effect of Eurasian snow cover on regional and global climate variations. J. Atmos. Sci., 46, 661-685.

Carleton, A. M., 1985: Synoptic and satellite aspects of the southwestern U.S. summer monsoon. J. Climatol., 5, 389-402.

_ D. D. Aarpenter, and P. J. Weser, 1990: Mechanism of interannual variability of southwest United States summer precipitation maximum. J. Climate, 3, 999-1015.

Castro, C. L., T. B. Mckee, and R. A. Pielke Sr., 2001: The relationship of the North American monsoon to tropical and North Pacific sea surface temperatures as revealed by observational analyses. J. Climate, 14, 4449-4473.

Comrie, A. C., and E. C. Glenn, 1998: Principal componentsbased regionalization of precipitation regimes across the southwest United States and northern Mexico, with an application to monsoon precipitation variability. Climate Res., 10, 201-215.

Daly, C., R. P. Neilson, and D. L. Phillips, 1994: A statisticaltopographic model for mapping climatological precipitation over mountainous terrain. J. Appl. Meteor., 33, 140-158.

Dettinger, M. D., D. R. Cayan, H. F. Diaz, and D. M. Meko, 1998: North-south precipitation patterns in western North America on interannual-to-decadal timescales. J. Climate, 11, 3095-3111.

Entekhabi, D. I., I. Rodriguez-Iturbe, and R. Bras, 1992: Variability in large-scale water balance and land surfaceatmosphere interaction. J. Climate, 5, 798-813.

Gershunov, A., and T. P. Barnett, 1998: Interdecadal modulation of ENSO teleconnections. Bull. Amer. Meteor. Soc., 79, 2715 2725.

— , and D. R. Cayan, 2003: Heavy daily precipitation frequency over the contiguous United States: Sources of climate variability and seasonal predictability. J. Climate, 16, 2752-2765. 
Gutzler, D. S., 2000: Covariability of spring snowpack and summer rainfall across the southwest United States. J. Climate, 13, 4018-4027.

—_, and J. W. Preston, 1997: Evidence for a relationship between spring snow cover in North America and summer rainfall in New Mexico. Geophys. Res. Lett., 24, 2207-2210.

Hales, J. E., Jr., 1974: Southwestern United States summer monsoon source-Gulf of Mexico or Pacific Ocean? J. Appl. Meteor., 13, 331-342.

Harrington, J. A., Jr., R. Cerveny, and R. Balling Jr., 1992: Impact of the Southern Oscillation on the North American Southwest Monsoon. Phys. Geogr., 13, 318-330.

Higgins, R. W., and W. Shi, 2000: Dominant factors responsible for interannual variability of the summer monsoon in the southwestern United States. J. Climate, 13, 759-776.

_- Y. Yao, and X. L. Wang, 1997: Influence of the North American monsoon system on the U.S. summer precipitation regime. J. Climate, 10, 2600-2622.

—, K. C. Mo, and Y. Yao, 1998: Interannual variability of the U.S. summer precipitation regime with emphasis on the southwestern monsoon. J. Climate, 11, 2582-2606.

$\mathrm{Hu}$, Q., and S. Feng, 2002: Interannual rainfall variations in the North American summer monsoon region: 1900-98. J. Climate, 15, 1189-1202.

Liang, X., D. P. Lettenmaier, E. F. Wood, and S. J. Burges, 1994: A simple hydrologically based model of land surface water and energy fluxes for GCMs. J. Geophys. Res., 99 (D7), 14 415-14 428

Lo, F., and M. P. Clark, 2002: Relationships between spring snow mass and summer precipitation in the southwestern United States associated with the North American monsoon system. J. Climate, 15, 1378-1385.

Matsui, T., V. Lakshml, and B. Small, 2003: Links between snow cover, surface skin temperature, and rainfall variability in the North American monsoon system. J. Climate, 16, 1821-1829.

Maurer, E. P., A. W. Wood, J. C. Adam, D. P. Lettenmaier, and B. Nijssen, 2002: A long-term hydrologically based dataset of land surface fluxes and states for the conterminous United States. J. Climate, 15, 3237-3251.
Meehl, G. A., 1994: Influence of the land surface in the Asian summer monsoon: External conditions versus internal feedbacks. J. Climate, 7, 1033-1049.

Mo, K. C., and J. N. Paegle, 2000: Influence of sea surface temperature anomalies on the precipitation regimes over the southwest United States. J. Climate, 13, 3588-3598.

Mock, C. J., 1996: Climatic controls and spatial variations of precipitation in the western United States. J. Climate, 9, 11111125.

Nijssen, B., R. Schnur, and D. P. Lettenmaier, 2001: Global retrospective estimation of soil moisture using the Variable Infiltration Capacity land surface model, 1980-93. J. Climate, 14, 1790-1808.

Pan, M., and Coauthors, 2003: Snow process modeling in the North American Land Data Assimilation System (NLDAS): 2. Evaluation of model simulated snow water equivalent. $J$. Geophys. Res., 108, 8850, doi:10.1029/2003JD003994.

Rowson, D. R., and S. J. Colucci, 1992: Synoptic climatology of thermal low-pressure systems over southwestern North America. Int. J. Climatol., 12, 529-545.

Shepard, D. S., 1984: Computer mapping: The SYMAP interpolation algorithm. Spatial Statistics and Models, G. L. Gaile and C. J. Willmott, Eds., D. Reidel, 133-145.

Shukla, J., and D. A. Mooley, 1987: Empirical prediction of the summer monsoon rainfall over India. Mon. Wea. Rev., 115, 695-703.

Small, E. E., 2001: The influence of soil moisture anomalies on variability of the North American monsoon system. Geophys. Res. Lett., 28, 139-142.

Stensrud, D. J., R. J. Gall, and M. K. Nordquist, 1997: Surges over the Gulf of California during the Mexican monsoon. Mon. Wea. Rev., 125, 417-437.

Walker, G. T., 1910: Correlation in seasonal variation of weather Mem. Indian Meteor. Dept., 21, 22-45.

Yeh, T.-C., R. T. Wetherald, and S. Manabe, 1984: The effect of soil moisture on the short-term climate and hydrology change-A numerical experiment. Mon. Wea. Rev., 112, 474490 . 